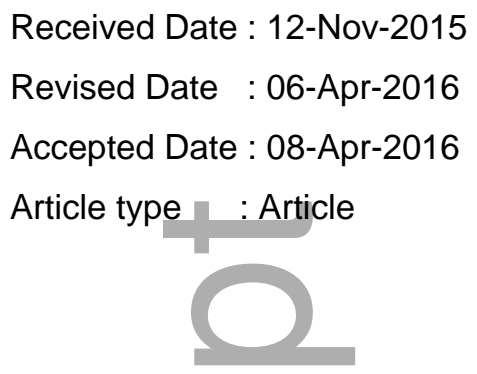

\title{
Micro-Computed Tomography and Shock Microdeformation Studies on (1) Shatter Cones
}

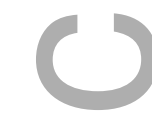

\author{
Patrice Tristan $Z_{A A G}{ }^{1,2^{*}}$, Wolf Uwe REIMOLD ${ }^{1,3}$ and Christy Anna HIPSLEY ${ }^{1,4}$
}

${ }^{1}$ Museum für Naturkunde Berlin - Leibniz Institute for Evolution and Biodiversity Science, Invalidenstrasse 43, Berlin 10115, Germany.

${ }^{2}$ Freie Universität Berlin, Institut für Geologische Wissenschaften, Malteserstrasse 74-100, 12249 Berlin, Germany.

${ }^{3}$ Humboldt Universität zu Berlin, Unter den Linden 6, Berlin 10099, Germany.

${ }^{4}$ School of BioSciences, University of Melbourne, Parkville VIC 3010, Australia.

*Corresponding author. E-mail: patrice.zaag@mfn-berlin.de

\section{ABSTRACT}

One of the aspects of impact-cratering that are still not fully understood is the formation of shatter cones and related fracturing phenomena. Yet, shatter cones have been applied as an impact-diagnostic criterion for decades without the role of shock waves and target rock defects having been elucidated ever. We have tested the application of the nondestructive micro-computed tomography $(\mu \mathrm{CT})$ method to visualize the interior of shatter cones in order to possibly resolve links between fracture patterns and shatter cone surface features (striations and intervening "valleys"). Shatter-coned samples from different impact sites and in different lithologies were investigated for their $\mu \mathrm{CT}$ suitability, with a shatter cone in sandstone from the Serra da Cangalha impact structure (Brazil) remaining as the most promising candidate because of the fracture resolution achieved. To validate the obtained CT data, the scanned specimen was cut into three orthogonal sets of thin sections. Scans with $13 \mu \mathrm{m}$ resolution were obtained. $\mu \mathrm{CT}$ scans and microscopic analysis unraveled an orientation of subplanar fractures and related fluid inclusion trails, and planar fracture (PF) orientations in the interior of shatter cones. Planar deformation features (PDF) were observed predominantly near the shatter cone surface. Previously undescribed varieties of feather features (FF), in the form of lamellae emanating from curviplanar and curved fractures, as well as an 'arrowhead'-like FF development with This is the author manuscript accepted for publication and has undergone full peer review but has not been through the copyediting, typesetting, pagination and proofreading process, which may lead to differences between this version and the Version of Record. Please cite this article as doi: $\underline{10.1111 / \text { maps.12673-2457 }}$

This article is protected by copyright. All rights reserved 
micro-lamellae originating from both sides of a PF, were observed. The timing of shatter cone formation was investigated by establishing temporal relations to the generation of various shock microscopic effects. Shatter cones are, thus, generated post- or syn-formation of PF, FF, subplanar fractures, and PDF. The earliest possible time for shatter cone formation is during the late stage of the compressional phase, i.e., shock wave passage, of an impact event.

\section{INTRODUCTION}

\section{Shatter cones at a glance}

Shatter cones were first described by Branco and Fraas (1905) as "Strahlenkegel" (radiation cones) and "Strahlenkalk" (radiation chalk / limestone) from the Steinheim Basin impact structure, Germany. They were, termed "shatter cones" by Dietz in 1947. Shatter cones are a unique, often conically or part-conically appearing fracture phenomenon that represents the only known meso- to macroscopic feature diagnostic for impact deformation, as it has only ever been observed in impact structures (e.g., Dietz 1960; French 1998; French and Koeberl 2010; Wieland et al. 2006; papers in this issue). Accordingly, shatter cones can serve to initially identify impact structures, as it has, for example, recently occurred in the case of the deeply eroded Keurusselkä impact structure of south-central Finland (Hietala and Moilanen 2004; Ferrière et al. 2010; Hasch et al. 2016, this issue). Ferrière and Osinski (2010) stated that shatter cones have been reported from at least half of the confirmed impact structures on Earth; an up-to-date summary of shatter cone occurrences is provided by Baratoux and Reimold (2016, this issue). These authors also review the previous hypotheses attempting to explain the processes on shatter cone generation. Besides occurring in natural impact structures, small shatter cones have been generated in nuclear bomb tests (Dietz 1960) and with shock experiments (Schneider and Wagner 1976; Kenkmann et al. 2012; Wilk and Kenkmann 2015; Wilk et al. 2016, this issue). Recently, occurrences of shatter cones have also been described from meteorites (McHone et al. 2012; Ferrière et al. 2013).

A shatter cone is a fracture surface showing striations that diverge from an apex or small apical area (Fig. 1A). The main features describing a shatter cone morphology are illustrated in Fig. 1 (A, B and C): the two outermost striations delimiting the lateral termination of a shatter cone, the apical angle, the lower termination; often a fracture, a striation, branching striations; horsetailing; and the size, i.e., the length between apex and base (Fig. 1B).

\section{Figure 1}

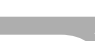

Shatter cones invariably show a concave and convex imprint of this fracture surface (Dietz 1947). This can be seen when fresh samples are broken apart (e.g., images of shatter cones in limestone, chert and sandstone from the Jebel Waqf as Suwwan structure (Jordan) by Kenkmann et al. 2010 and in Reimold and Koeberl 2014). Sizes vary from < 5 millimeters in experimentally shocked specimens (Kenkmann et al. 2012; Schneider and Wagner 1976) up to 12 meters as observed in the field (e.g., Dietz 1960; Dressler et al. 1999; Fackelman et al. 2008). 
Surface striations never cross each other but can run into each other, and the ends of striations can be the source of new shatter cones or a point from which arrays of striations radiate off. In other words, striations evolve and fan-out from other striations. This effect has been termed horsetailing (Manton 1965; see also Kenkmann et al. 2016, this issue).

Typically, the morphology of shatter cones is not truly conical; however, a conical shape has been the simplest approximation for their morphological characterization. Dietz (1947), as well as Johnson and Talbot (1964), simply described shatter cones as being of a conical shape; Sagy et al. (2004) described them as curved, oblate, and spoon-like. Wieland et al. (2006), Wieland (2007), and Zaag (2014), on the basis of morphometric stereoplot interpretations, found them not to be of a conical shape, like Baratoux et al. (2014) and Baratoux et al. (2016, this issue). These authors report detailed 3D morphometric analysis and classification of shatter cone surface geometries and found that they could be better described by more complex quadric surfaces (such as hyperboloids and paraboloids). Full apparent cones of $360^{\circ}$ are extremely rare; usually only partial cone-like structures are observed (Fig. 1A, 2). The apex is the locus from which a shatter cone seemingly originates; it can be represented by a point (e.g., grain) or an area / plane (e.g., a portion of a bedding plane or a joint), or even by an apical line / a fracture plane. In recent years we have observed that apical areas are invariably polygonal and limited by marginal fractures, rather than being eireular (e.g., Wieland et al. 2006; Wieland 2007; Zaag 2014). Apical angles can vary, not only on the scale of an outcrop, but within the distance of some millimeters. The variety of apical angles reported in the literature ranges from $<70^{\circ}$ (Milton 1977) to $160^{\circ}$ (Wieland 2007).

Shatter cones can form in any kind of consolidated rock. Finer-grained host lithologies bear more intricately developed shatter cones with finer striations (e.g., Johnson and Talbot 1964; Manton 1965; Nicolaysen and Reimold 1999; Baratoux and Reimold 2016, this issue), i.e. the amplitude and wavelengths of striations become larger in coarser-grained lithologies (Gibson and Spray 1998). Although distinct shatter cone developments have been observed by W.U.R. and P.T.Z. in medium-grained granite gneiss from the Vredefort Dome, and in medium- to coarse-grained granitoids in the Keurusselkä structure by Hasch et al. (2016, this issue), in recent years. The fracture surface of shatter cones can show melt, displacement, and separation (e.g., Gay 1976; Gay et al. 1978; Gibson and Spray 1998; Nicolaysen and Reimold 1999; Pittarello et al. 2015; Kenkmann et al. 2012; Hasch et al. 2016, this issue).

Shatter cones have been found in central uplift areas, as well as in crater rim zones of impact structures, in clasts of impāct ejected material, and on clasts in crater-fill breccia. Shatter cones have never been reported from settings that were subjected to endogenic processes - only. Based on associated shock metamorphic deformation of the shatter coned lithologies, it has been estimated that they can be formed in the shock regime between 2 and 30 GPa (French 1998), possibly even up to 45 GPa (Nicolaysen and Reimold 1999).

Some authors have held that field measurements of striation directions on several cone structures would define a so-called master-cone, the apex of which was oriented towards the source of energy release, or the point of impact when this axis orientation would be restored to the prior-to-impact orientation of the host stratum (e.g., Dietz 1960; Hargraves 1961; Manton 1965; Johnson and Talbot 1964; Roddy and Davis 1977, inter alia). These theories imply that shatter cones develop at an early stage of impact, prior to modification of the original stratigraphy. Detailed recent field studies that have focused on striation orientations on all cone structures in a given rock volume 
have invariably shown that such a restoration of apex orientations to a single direction is not permissible (e.g., Nicolaysen and Reimold 1999; Wieland et al. 2006). For example, shatter cones occurring within narrow environs of each other (centimeters to decimeters) frequently point in opposite or very different directions (Nicolaysen et al. 1999; Zaag 2013; Zaag 2014; Hasch et al. 2016, this issue) and can even be joined at their opposite-directed apices.

Finally, Nicolaysen and Reimold (1999) carried out detailed jointing and shatter cone orientation analysis and found that both phenomena were seemingly related (see also Hasch et al. 2016, this issue). They found that strata with abundant shatter cone development also contained multiple sets of subparallel, planar to curviplanar joints, which they termed MSJS (multiply-striated joint sets).

\section{When and how do shatter cones form?}

The exact timing of shatter cone formation in the cratering event, as well as the exact mechanisms involved in their formation, are still under debate. Dietz (1947) was the first to propose a timing of their formation during the early, compressional phase of an impact event. Nicolaysen and Reimold (1999) allowed for the possibility that shatter cones and related multiply striated joint sets (MSJS) were generated relatively late in the formation of the Vredefort impact structure (South Africa), i.e. after the compressional phase of an impact event. Many hypotheses for the formation of shatter cones have been postulated in the last decades. All of them agree that shatter cones form as a shock wave encounters heterogeneity in a rock (e.g., Johnson and Talbot 1964; Baratoux and Melosh 2003; Sagy et al. 2004; Dawson 2009). The heterogeneity causes reflection, scattering, and /or refraction of the shock wave, which may locally cause overstress in the host rock until mechanical failure occurs. A heterogeneity or discontinuity can be an area or a point of anomalous size or density, including a fracture or joint. The processes that could be involved in the formation of shatter cones are outlined in Baratoux and Reimold (2016, this issue); the models of Johnson and Talbot (1964), Gash (1971), Baratoux and Melosh (2003), Sagy et al. (2004), Dawson (2009) and Kenkmann et al. (2016, this issue) are explained and discussed in depth.

\section{This investigation}

The aim of our study was to test the micro-computed tomography $(\mu \mathrm{CT})$ technique as a non-destructive method to visualize structures (fractures and micro-fractures) in the interior of shatter cones and then attempt to link them to surface features on shatter cones (ridge and groove patterns). It was hoped to be able to explain the apparent relationship between shatter cone striations and occurrence of joints and micro-joints. The relationship between shatter cones and MSJS was to be investigated. In order to validate the obtained $\mu \mathrm{CT}$-3D volume graphics a series of thin sections, cut in three perpendicular orientations, was examined by polarizing microscopy. This lead to subsequent detailed observations made on shock microdeformation. Results of both these analytical approaches are presented here.

\section{SAMPLES AND METHODOLOGY}


Four shatter cone samples from four different impact structures that had been formed in sandstone, dolostone, quartzite, and gneiss, respectively, were selected. A sample in dolostone from the Haughton impact structure (Robertson and Mason 1975) in Canada was scanned at the $\mu$ CT facility of the Museum für Naturkunde Berlin (MfN), Germany. The sample (courtesy of B. Dressler) displayed a very well developed shatter cone showing intricately developed striations (Fig. 1A). A quartzitic shatter cone sample from the Vredefort impact structure (South Africa) was derived from the Maraisburg Formation (Central Rand Group) at the famous Schoemansdrif Bridge location (e.g., Nicolaysen and Reimold 1999), which is situated in the western collar of the Vredefort Dome. A third shatter cone, developed in gneiss from the Santa Fe impact structure (USA), was obtained courtesy of Elmar Buchner (Neu-Ulm). Several millimeters sized splits of the latter two samples were scanned at high resolution of 2.7 micrometer at the Ludwig-Maximilians-Universität (LMU) Munich, Germany. The samples from Vredefort, Haughton and Santa Fe turned out to be unsuitable for $\mu \mathrm{CT}$ investigations. Even though high resolution scans were obtained, these lacked optimum contrast and were interspersed with artefacts. Additionally, and even more important, was that their inner fracture patterns could not be resolved, likely because inner fractures were not existent due to closure of fractures as a consequence of diagenetic overprint, and/or because of the material properties of the samples. Especially at sample's density or the high atomic numbers of the mineral-forming atoms could hinder the effective penetration by X-rays.

Finally, a 65x16x15 mm sized shatter cone sandstone sample, courtesy of M. A. R. Vasconcelos (Salvador, Brazil), from the Serra da Cangalha impact structure in Brazil turned out to be the most promising candidate with respect to the selection criteria introduced below, for the study at MfN. Serra da Cangalha is a complex impact structure (centered at $\sim 8^{\circ} 05^{\prime} \mathrm{S}$ and $46^{\circ} 52^{\prime} \mathrm{W}$ ) located in NE Brazil. It is $13.7 \mathrm{~km}$ in diameter and younger than 250 $300 \mathrm{Ma}$, according to the youngest impact affected strata (Kenkmann et al. 2012). The sample was collected within the innermost depression of the central uplift area, at $8^{\circ} 4^{\prime} 38.72^{\prime \prime} \mathrm{S}$ and $46^{\circ} 51^{\prime} 45.88^{\prime \prime} \mathrm{W}$, in a block of sandstone (Vasconcelos et al. 2013; Kenkmann et al. 2011). As the sandstone blocks at this location were not found in situ, a correlation (Vasconcelos et al. 2013) with regard to their original position in the inner crater is impossible. However, the possibility that the blocks were sampled at, or close to, their original place appears a reasonable assumption.

The investigated sample mostly consists of quartz. It also contains ca. 3 vol\% of accessory minerals (hornblende, zircon, feldspar, phyllosillicate, as well as iron, manganese, and titanium oxides). Chert with adhering quartz grains was the only lithic rock fragment type found, at ca. $1 \mathrm{vol} \%$. This terrigenous clastic sandstone is classified as a quartz arenite according to Pettijohn (1975). The presence of rare single sets of PDF in rocks of the central uplift of Serra da Cangalha indicates a shock pressure regime of, at maximum, some $10 \mathrm{GPa}$ (Vasconcelos et al. 2013). Such a low degree of shock is consistent with the overall geological assessment of the structure that is quite deeply eroded.

Micro-computed tomography $(\mu \mathrm{CT})$ is a non-destructive method of creating 3D images of the interior of a body. In principle, the object of interest is positioned between an X-ray source and detectors. A detector visualizes the degree of attenuation of the X-rays passing through the scanned object in a so-called radiograph or view (e.g., Ketcham and Carlson 2001). Grey values correspond to different attenuation coefficients. During reconstruction all obtained sonograms (a radiograph including its projection data) of a scan are converted into 2D cross-sectional images (slices) with a mathematical process. By volume rendering, slices are combined to a 3D volume graphic (e.g., 
Ketcham and Carlson 2001; Mees et al. 2003; Long et al. 2009). 3D volumes are termed voxels (volumetric pixels) the 3D equivalent of 2D pixels. Usually, when studying the slices in detail, one creates three stacks of slices, in which each stack is oriented parallel to the $\mathrm{x}, \mathrm{y}$, and $\mathrm{z}$ axes of an arbitrary coordinate system.

The required properties for a sample to be optimally scanned are: being small in size (depending on the capacity of the utilized $\mu \mathrm{CT}$ chamber and the power of the X-ray source), of low density (ability of the X-ray beam to penetrate the sample), preferably of cylindrical shape (to avoid different lengths of X-ray pathways). Additionally, the sample needs to have properties making a microscopic petrographic study for the verification of the scanning results possible. For the petrographic study, a mineral composition suitable for the detection of micro-shock deformation features was required. Shatter cones should be developed as intricately as possible for the study of the fracture surfaces; therefore, the lithology needed to be fine-grained and relatively homogeneous.

At LMU, for the two samples from Vredefort and Santa Fe impact structures respectively, a Phoenix v/tome/x s $\mu$-CT scanner was utilized. This CT scanner uses a high-power nanofocus X-ray tube which is capable of creating scans with a maximum resolution of down to $2 \mu \mathrm{m}$ per Pixel / Voxel. We performed CT-scans on a Phoenix $\mathrm{X}$-ray Nanotem M $\mu \mathrm{CT}$ (or nano CT) at the MfN, Berlin. For the scan of a 65x16x15 mm sized sample from Serra da Cangalha a tungsten target was utilized, two $0.1 \mathrm{~mm}$ thick copper plates were used for pre filtering of the X-ray beam at $90 \mathrm{kV}$ and $230 \mathrm{~mA}$. For reconstruction of the 3D volume the software Phoenix Datos|x (Version 1.5.3.1) was used. High resolution scans of $13 \mu \mathrm{m}$ per voxel were obtained. We were also able to illustrate the morphology/topography of the sample surface in the 3D volumes (Fig. 2) with Volume Graphics Studio MAX 2.0.

\section{Figure 2 \\ Micropetrography}

For the petrographic studies a series of forty-seven polished thin sections was prepared from the sandstone sample. Thin section series were cut parallel to the $\mathrm{x}, \mathrm{y}$ and $\mathrm{z}$ axis of the specimen, in accordance with the generated image stacks of the $\mu C T$ slices. Spacings between two parallel thin sections were of the order of $1 \mathrm{~mm}$. Twenty-five sections were cut parallel to the Z-Y and Z-X planes; these thin sections are referred to as longitudinal sections. Twenty-two thin sections were cut parallel to the Y-X plane and are referred as transversal sections. The thin sections were investigated with a standard polarizing microscope and then compared with the CT slices.

\section{Definitions of pertinent microdeformation types}

Planar fractures (PF) are (sub)planar open fissures, cracks or cleavages that usually occur in 1 to $>3$ sets per grain with spacings between fractures of more than $20 \mu \mathrm{m}$ (Stöffler and Langenhorst 1994). As similar fractures can be formed in non-impact related settings, PF cannot be used independently as proof of hypervelocity impact (e.g., French 1998; French and Koeberl 2010). However, if PF are found in high abundance in quartz, it may well be worthwhile to further scrutinize a thin section for other, possibly impact-diagnostic evidence. In combination with other impact-diagnostic features, PF are highly likely caused by an impact event (Stöffler and Langenhorst 1994). PF 
never cross grain boundaries; they typically show spacings wider than that of planar deformation features (PDF; French and Koeberl 2010). PF form earlier than PDF (next paragraph) but never intersect them (Engelhardt and Bertsch 1969). They form at shock pressures $>5$ and $<20$ GPa (Deutsch et al. 2015). It has been suggested that sheared PF are oriented at $\sim 45^{\circ}$ to the main stress axis (Poelchau and Kenkmann 2011).

Planar deformation features $(P D F)$ in quartz and other silicate minerals are the most frequently utilized diagnostic (micro)-feature for the confirmation of hypervelocity impact on the Earth surface (e.g., Ferrière et al. 2010, Losiak et al. 2016). PDF occur as single or multiple sets of parallel, strictly planar optical discontinuities that are, in the microscope, recognizable as thin amorphous lamellae or as planes decorated with tiny fluid or solid inclusions (so-called decorated PDF). They can be up to approximately $2 \mu \mathrm{m}$ wide (Stöffler and Langenhorst 1994); they never cross grain boundaries (French and Koeberl 2010). They are usually spaced at 2-10 $\mu \mathrm{m}$ and tend to be spaced closer and are more homogeneously distributed in the host grain with increasing shock intensity (Stöffler and Langenhorst 1994). Some authors stated that in rare cases they can be slightly bent or diverge from being parallel (Grieve et al. 1996; Stöffler and Langenhorst 1994; Kowitz et al. 2013a), however, the term PDF then would be misleading. We believe that PDF can appear bent but then the host crystal lattice has been disturbed subsequently to the impact event (e.g., Trepmann 2008; Reimold et al. 2014). Decorated PDF are thermally annealed, originally nondecorated PDF (Grieve et al. 1996). It has been widely held that different crystallographic orientations of PDF are developed at different shock pressures (e.g., Huffman and Reimold 1996). Based on the orientation of the PDF to the quartz c-axis a shock pressure calibration can be attempted (Stöffler and Langenhorst 1994; French and Koeberl 2010). Kowitz et al. (2013a, b) reported that porosity in sandstone is a critical parameter that determines at what shock pressures the onset of formation of diagnostic shock features (e.g., diaplectic quartz glass, $\mathrm{SiO}_{2}$ melt , and PDF) occurs. They noted first PDF development at $17.5 \mathrm{GPa}$ for a Seeberger sandstone (L5); a arenitic quartz sandstone with an average porosity of 12.2 to 19.2 Vol.-\%. Huffman and Reimold (1996) reported first development of rare PDF in a sandstone experimentally shocked at $8 \mathrm{GPa}$.

Whether feather features (FF) are a diagnostic shock metamorphic effect is still discussed in the scientific community. However, reports of this fracturing phenomenon to date are from rocks in impact structures only. Poelchau and Kenkmann (2011) defined FF as a combination of a PF, from which a group of thinly spaced lamellae (micro-fractures) branch off - in their original definition, to only one side. These lamellae can be slightly curved, are much shorter than the fractures from which they emanate, have spacings between 2 and $10 \mu \mathrm{m}$, and, thus, optically bear a similarity to PDF (although they are clearly recognizable as fractures). FF lamellae were related by these authors to shear along crystallographically controlled micro-fractures. The most common crystallographic orientations of PF hosting lamellae are (0001), $\{10 \overline{1} 1\}$, and $\{11 \overline{2} 2\}$; whereas $\{10 \overline{1} 3\}$ and $\{10 \overline{1} 2\}$ orientations only occur in rare cases. More details about the frequency and possible orientations of planar micro-structures comprising FF are given in Poelchau and Kenkmann (2011; their figure 2). FF were found by Poelchau and Kenkmann (2011) in shock metamorphosed rocks of some 26 impact structures ranging from 1.2 to $65 \mathrm{~km}$ in size. In experimentally shocked material FF were formed at pressures of ca. 7-10 GPa (Poelchau and Kenkmann 2011) but more precise upper and lower limits need to be confirmed by further work.

Fluid inclusion planes (FIP) are not a distinct shock metamorphic effect but due to their high abundance in the investigated sample, they deserve mentioning. They result from healing of cracks and fissures in the presence of 
fluids; i.e., FIP represent fossilized fluid pathways (e.g., Roedder 1984). They can occur along sets of fractures, are predominantly oriented perpendicular to the least principal compressive stress axis, and can therefore be utilized to determine paleo-stress orientations (Lespinasse 1999). In a thin section they can only be observed in twodimensional form, so that they are addressed as fluid inclusion trails (FIT). Annealing of decorated PDF may also lead to the formation of planar FIT.

The crystallographic orientation of (shock) features was determined with a universal-stage (U-stage) microscope. A four axial (Leitz) U-stage mounted on a Leitz polarizing microscope was utilized. Ferrière et al. (2009) undertook a systematic study on indexing PDF with a program utilizing a new version of the commonly used stereographic projection template. This template includes the positions of five additional typical PDF sets, which would, utilizing the old method, remain unindexed and therefore could enlarge the measurement error. The indexing was done with the aid of the 'Automated Numerical Index Executor' (ANIE; version 1.0), a program provided in Huber et al.'s (2011) supporting information. For the indexing, a maximum error of $5^{\circ}$ was applied as recommended by, e.g., Ferrière et al. (2009).

\section{RESULTS}

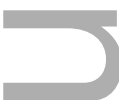

The first attempts to scan a irregularly shaped, 60x40x5 mm sized sample from the Haughton impact structure, showing intricate striations failed due to the high content of dense dolomite $\left(\mathrm{CaMg}\left(\mathrm{CO}_{3}\right)_{2} ;\right.$ density $2.83-$ $2.87 \mathrm{~g} / \mathrm{cm}^{3}$; high attenuation coefficient) and also due to its irregular shape that was different from an 'ideal' cylinder. The obtained scans were extremely noisy and extensive attempts to find the best-suited scanning parameters and to minimize artefacts, during reconstruction, were fruitless. Thus, we focused on the more promising (see Samples and Methodology Section) sandstone sample from Serra da Cangalha; being of lower density ( 2.2 $2.8 \mathrm{~g} / \mathrm{cm}^{3}$ ) and additionally of a more suitable shape (more elongated like a cylinder). To obtain a maximum resolution for the scan, the $65 \mathrm{~mm}$ high (longest axis) sample was scanned applying a multi-scan method. The sample was scanned in four (longitudinal) sections, each with an overlapping part (cf. Fig. 2, Fig. 4A) to be able to refit / recombine the four 3D volumes after reconstruction of the raw data. The recombination of the different parts turned out to be more complicated as expected at the time of scanning; the utilized software was not able to automatically recombine the sections. The single sections had to be refit manually. The obtained (combined) 3D volume (Fig. 2) was then investigated as (three) 2D stacks of slices. Each of these stacks was oriented parallel to the axis of an arbitrary coordinate system (X, Y and Z) which were chosen to be the same as those of the subsequently prepared thin sections.

\section{Surface investigation}

To validate the quality of the $\mu \mathrm{CT}$ scans (Fig. 3A; Fig. 4A), flatbed scans of thin sections (Fig. 3B; Fig. 4C) were compared with the corresponding slices (Fig. 3C; Fig. 4B). Main fractures or the shatter cone surfaces could be well visualized in all scans, as in the $\mu \mathrm{CT}$ slices; however, we were not able to resolve the entire micro-fracture pattern. The CT slices (Fig. 3A) lack optimum contrast and are, after reconstruction and rendering, interspersed with 
artefacts such as ring, star, or streak artefacts (Ketcham and Carlson 2001; Mees et al. 2003). The application of a Region of Interest (ROI) function was tested, in order to visualize only the fractures and micro-fractures. In a ROIfunction, the software automatically indicates certain grey values (corresponding to specific densities) in an a priori chosen interval. Unfortunately, this function turned out not to be applicable, as either the entire sample, or almost nothing, was indicated.

\section{Figure 3}

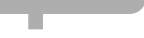

During examination of the thin sections, it was not clear whether a void found was of primary origin or an effect from preparation. In a cropped 3D volume (Fig. 4A) the void was recognized, as well as in the slices (Fig. 4B) and could be correlated with the corresponding thin section (Fig. 4C).

\section{Figure 4}

\section{Fracturing}

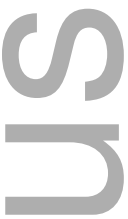

Fractures describing the 'surface' of shatter cones or those closely related to them are addressed as main fractures throughout this paper. Apart from the main fractures, the most prominent fracture pattern observed are linearly arranged sets of subplanar fractures, originally micro-joints now predominantly healed to fluid inclusion trails (FIT). They occur throughout the entire thin sections, both directly adjacent to main fractures and away from them. PF are also abundant but by far not as abundant as subplanar fractures. A single quartz grain can be intersected by PF of multiple orientations. They can be found more often in close vicinity to main fractures or directly along them, and are less abundant in 'distal' areas. More than $50 \%$ of the observed PF occur close to main fractures and are oriented sub-perpendicular to them, whereas the remaining PF predominantly occur at acute angles of some $45^{\circ}$ to the main fractures.

Main fractures that utilize PF to propagate - i.e., shatter cone surfaces that closely follow the orientations of PF - were also observed, which would place the formation of main fractures after the formation of PF. Often PF are linked to dense lamellae on one side of them, thus forming FF. Especially along the FF, displacement of a few micrometers as well as separation can be observed. Special types of FF were also found (see below).

PDF are by far less abundant than the afore-mentioned fractures. They usually occur only in narrow areas along the inner margins of host quartz grains and only very rarely they are seen to penetrate entire grains. PDF are also predominantly localized in close vicinity to main fractures. In rare cases, subplanar fractures, PF, FF and PDF were all observed within one and the same quartz grain.

The most abundant micro-fractures have a planar to subplanar character. Almost all these fractures form FIT (Fig. 5). In places, linear FIT radiate from a tiny area. One exact point from where they all originate could, however, not be discerned. The FIT in this area are limited by a NE to SW trending main fracture (Fig. 5B) and the 'actual' surface of a shatter cone (Fig. 5B, top right), but they can often only be tracked for distances of some 0.5 to $1 \mathrm{~mm}$ 
from the main fracture. However, in Fig. 5B (bottom left) FIT are oriented at acute angles to the surface of the shatter cone, whereby they are oriented sub-perpendicular (Fig. 5B, top right).

In close vicinity of the apex of the shatter cone; fractures follow the shape of the shatter cone, they are not controlled by mineral grain margins or other areas of weakness. Fractures further away from the shatter cone's apex predominantly run around grain margins.

Shard-like mechanical spalling ("percussion cracks") preferably observed at the margins of thin sections (Fig. 5B, bottom) were most probably created during the thin section preparation process as a result of stress relief after grinding. They are not related to the shatter-coning or other shock metamorphic deformation, and for that reason they are not further considered here.

\section{Figure 5}

\section{Shock features}

\section{Planar fractures and feather features}

During examination of the thin sections many FF were found. In general, they are characterized in agreement with the criteria established by Poelchau and Kenkmann (2011), i.e., they comprise a PF from which parallel lamellae (micro-fractures) emanate to one side (Fig. 6A). In this image, the lamellae are spaced at up to 10 $\mu \mathrm{m}$, with a maximum length of $\sim 35 \mu \mathrm{m}$. At the grain margin, the PF shows a displacement of a few $\mu \mathrm{m}$. The lower part of the intersected quartz grain shows relative movement to the top left; with a sinistral shear sense (Fig. 6A). A displacement of subplanar or curviplanar fractures that intersect the $\mathrm{PF}$ at an angle of about $55^{\circ}$ was not detected. It appears that the PF and subplanar to curviplanar micro-fractures formed contemporaneously (Fig. 6A) or the latter formed after the PF. Lamellae, on the other hand, overprint the subplanar fractures and, thus, must have evolved after the subplanar micro-fractures and PF.

In contrast to previous observations, $\mathrm{FF}$ with their lamellae emanating from clearly nonplanar fractures were also found (Fig. 6B and C). A subplanar fracture with a wavy appearance and lamellae emanating at an angle of $40^{\circ}$ to one side was observed. Note that the lengths of the feathers somewhat trace the wavy character of the fracture (Fig. 6B). FF development along a curved fracture was noted as well (Fig. 6C). Both grains occur at the same fracture. One of us, WUR, reports just having observed FF with distinctly nonplanar fractures from which the microfractures emanate in a number of quartz and quartzitic clasts in polymict impact breccia from the Araguainha structure in Brazil.

A quartz grain of some $300 \mu \mathrm{m}$ width is framed by a bifurcating main fracture that reunites some $200 \mu \mathrm{m}$ from the grain (outside the field of view of Fig. 6D, to the right). The area of Fig. 6D reflects an area of localized high stress. Curved fractures and PF with emanating lamellae are abundant (at least nine FF occur within an area of ca. $1.2 \mathrm{~cm}^{2}$ ), of which all but two are oriented at approximately $85^{\circ}$ to the main fracture; this shatter cone surface trends NE to SW (outside of the field of view of Fig. 6D). Subplanar healed fractures (FIT) are even more abundant than FF. A single quartz grain contains five FF, showing lamellae emanating from a curviplanar fracture (Fig. 6D), which is in contrast to the Poelchau and Kenkmann (2011) statement that FF lamellae only emanate from rather 
straight PF. The investigated quartz grain (Fig. 6D and E) is full of fluid inclusion trails with random orientations. Lamellae emanating from the topmost fracture of the quartz grain (Fig. 6D) overprint subplanar fractures and, thus, must be younger. Subplanar fractures and PF never cross or intersect each other; suggesting that they formed at the same time. Only the lowermost and the most prominent curviplanar fractures caused detectable displacement.

Figure $6 \mathrm{E}$ shows a curviplanar fracture $(\mathrm{CPF})$ with lamellae indicating a sinistral shear sense. In contrast, a shorter $\mathrm{CPF}$ with lamellae in the same figure indicates a dextral shear sense. The shorter CPF emanates from the lamellae-free side of the longer CPF. A hypothesis for the formation of this is provided in the Discussion section.

In a quartz grain that is crosscut by a PF poorly developed (FF) lamellae are variably oriented parallel to subparallel to each other and are - surprisingly - not always connected to the PF. Some lamellae are even bifurcated (Fig. 6F).

\section{Figure 6}

A complete 'feather-like' FF with sets of micro-fractures emanating from both sides of the 'quill'-forming $\mathrm{PF}$ was found in one of the longitudinally cut thin sections (Fig. 7A-C), in a quartz grain a few millimeters away from the features shown in Fig. 8A, B and C. The existence of such a double-sided, arrowhead-like FF was not considered by Poelchau and Kenkmann (2011), and does not comply with their hypothesis for the formation of FF (see Discussion and Conclusions sections). The direction of shear movement is top of the grain (Fig. 7A and C) to the left - a sinistral shear sense. Poelchau and Kenkmann (2011) suggested that the acute angle formed by a PF and the lamellae emanating from it point into the direction of shear movement. Note that the angle enclosed by PF 1 with L 1 and L 2 (Fig. 7) indicates shear movement in the same direction - clearly this could not have been initiated contemporaneously. Under the optical microscope, the lamellae appear to originate from a PF at an angle of $\sim 45^{\circ}$; the PF itself is oriented at about $87^{\circ}$ to the closest main fracture and is $\sim 240 \mu \mathrm{m}$ long. Displacement by ca. $10 \mu \mathrm{m}$ along the PF is visible (Fig. 7C). The crystallographic orientation of PF 1 (0001), L $1\{11 \overline{2} 1\}$ and L $2\{10 \overline{1} 1\}$ have been determined by U-stage microscopy. This reveals that the double-sided FF does not represent a cutting effect, as suggested by one of the reviewers.

Another FF was observed showing a displacement by $5 \mu \mathrm{m}$ and indicating the same dextral shear sense as the lower 'feather-like' FF of Fig. 7C. Subplanar fractures and FIT are overprinted by the lamellae, indicating that they pre-date the formation of lamellae.

\section{Figure 7}

Two quartz grains intersected by a main fracture along their elongated axis are shown in Fig. 8. The main fracture (Fig. 8A, dashed line) displaces the grain by about $25 \mu \mathrm{m}$ and separates it by $30 \mu \mathrm{m}$ along a planar fracture Fig. 8A, B and C. Lamellae forming a FF emanate from this planar section. In the quartz grain adjacent (on bottom, in Fig. 8C) to the first described grain, a PF occurs as well (black line). Under the optical microscope, it is oriented at $70^{\circ}$ to the planar section of the main fracture. PF 1, L 1, PF 2 and L 2 are all differently oriented to their host grain's c-axis (Fig. 8C). However, PF 1 and PF 3 (Fig. 8B) show the same $\{10 \overline{1} 1\}$ crystallographic orientation. Another 
quartz grain is equally displaced by a main fracture along a PF (Fig. 8D). Lamellae (L) overprint a subplanar fracture (SF) in Fig. 8D.

\section{Figure 8}

The crystallographic orientation of PF and related micro-fractures (FF) towards the C axes of their host quartz grains were measured and indexed. PF with (0001), $\{10 \overline{1} 1\},\{10 \overline{1} 3\},\{10 \overline{1} 4\},\{11 \overline{2} 2\}$ orientations were. FF lamellae with the following orientations were detected: $\{51 \overline{6} 0\},\{51 \overline{6} 1\},\{10 \overline{1} 1\},\{10 \overline{2} 1\},\{11 \overline{2} 1\}$, and $\{21 \overline{3} 1\}$.

Some of the transversal thin sections are highly fractured by multiple main fractures (shatter cone surfaces). FF are poorly to very well developed within a few millimeters from a main fracture. An overall finding is that in some thin sections the PF are randomly oriented with regard to the shatter cone.

\section{Planar deformation features}

Quartz grains containing PDF are irregularly distributed within the sample. They occur rather in the outer parts of their host grains (Fig. 9D), and only sometimes close to main fractures. As illustrated in Fig. 9, they are predominantly decorated. They mainly occur as one set, and only rarely, as two sets per host grain. Their visualization can be difficult - only when changing the microscope focus all sets will appear. Grains sometimes show two sets or more; however, under crossed polarizers it becomes apparent that subgrains are differently oriented and, therefore, PDF cannot be considered as multiple sets. The low number $(<2)$ of sets per host grain does not indicate very high shock pressure (Fig. 9A, B and C), generally of less than $20 \mathrm{GPa}$. A fractured quartz grain showing two differently oriented sets of PDF (Fig. 9A and C) is divided by a micro-fracture, but both subgrains are not rotated against each other; their c-axes are oriented parallel to each other, as also shown by the mutual extinction behavior.

\section{Figure 9}

Probably the most significant finding of PDF in this study, because it allows setting limits to the timing of shatter cone emplacement, is shown in Fig. 10A and B. A quartz grain containing one set of decorated PDF is cut by a main fracture. The grain shows displacement by $70 \mu \mathrm{m}$. Both parts of the grain become extinct in the same position under crossed polarizers. The PDF in both parts of the grain were measured separately - their crystallographic orientation is the same at $\{10 \overline{1} 4\}$. The orientation of the main fracture was additionally determined with U-stage microscopy but it could not be indexed. The crystallographic orientation of PDF was determined; $(0001),\{10 \overline{1} 3\}$, $\{10 \overline{1} 4\}$, and $\{11 \overline{2} 1\}$ orientations were detected.

\section{Figure 10}

\section{DISCUSSION}


To recapitulate, thin sections of the shatter cone specimen from Serra da Cangalha were examined by microcomputed topography; three stacks of $2 \mathrm{D} \mu \mathrm{CT}$ cross-sectional images were studied.

Thereafter the micro-CT findings were further investigated by thin section petrography. Variants of FF, not described before, were found. Furthermore, subplanar fractures and FIT, PF, FF, and PDF were studied with regard to their orientation in relation to main fractures (shatter cone surfaces), as well as the character of the main fractures themselves. Temporal relations between shock metamorphic effects and the formation of shatter cones were established.

\section{Limitations of studying shatter cones with $\mu \mathrm{CT}$}

Initially CT scanners were developed to obtain a view of the inside of a human body. The beam energy required could be low due to the relatively low density of the scanned material, the high density contrast between bones and tissue, and the need to visualize their 'surface' and not their interior. Here, the aim was to visualize a rock sample's internal features (micro-fractures) instead of its surface. A more or less homogeneous rock, a material with high density but low density contrast, such as relatively pure sandstone, is challenging to scan. The (micro-)fractures should, however, show a distinct density contrast to the hosting lithology - as long as they were not subjected to secondary overprint, such as infilling during diagenesis.

Grey values of CT images correspond to the density - closely related to the atomic number of materials, respectively their attenuation coefficients (Ketcham and Carlson 2001). Additionally, the visualization of these properties as grey values depends on the intensity of the X-ray beam. They are generally not referenced, and a certain grey value is only specific for the adjusted parameters of a particular scan. To reference the grey values for each mineral, an extensive number of scans and their validation would have been required; this was beyond the scope of this initial exploratory work.

An attenuation coefficient is not only dependent on material properties but also on the energy of X-ray radiation. Polychromatic X-ray radiation creates attenuation coefficients different from that of monochromatic X-ray radiation (Mutina and Koroteev 2012). A Phoenix X-ray Nanotem $\mu C T$, as used for this study, applies an X-ray source creating polychromatic radiation. The NIST (National Institute of Standards and Technology, U.S. Department of Commerce) database comprises a list of minerals and their standard attenuation coefficients (Hubbell and Seltzer 1995). To use such a database would be of great value for quantitative analyses. Unfortunately, this database is referenced for monochromatic X-ray radiation (Mutina and Koroteev, 2012) and therefore it could not be utilized. In general, X-rays are always polychromatic, comprising a wide range in energy, as long as they are not created by radioactive decay (Mees et al. 2003). The monochromatization of X-rays by diffraction eliminates problems of polychromatic X-rays, such as generation of artefacts in the CT images and the above mentioned problems with quantitative analysis. However, it involves a great decrease in intensity of the $\mathrm{X}$-ray beam and is, therefore, only feasible for systems with high initial intensities, such as linear electron accelerators and synchrotron $\mathrm{X}$-ray tomography installations (Mees et al. 2003).

Healed (micro-)cracks, fractures or fissures possibly have an influence on the quality of a scanned 3D volume, as X-rays could be refracted on them and then create wrong attenuation values at places, i.e., they could be 
responsible for an overall blurring effect. Here, many of these fractures are present in the form of the subplanar fractures and FIT. Due to their high abundance throughout the sample and their linear arrangement, FIT could have caused an overall reduction of image quality.

For the $\mu \mathrm{CT}$ scans undertaken at MfN, a tungsten target instead of a molybdenum target was selected for Xray generation because of its ability of creating a more energetic beam. A more energetic beam corresponds to X-ray photons with shorter wavelengths - this is required to penetrate the relatively dense mineral components of solid rocks. Tests with carbonate hosted shatter cones (because of the more intricate development of shatter cones) from the Haughton impact structure, Canada, showed that they are composed of too dense material to be adequately penetrated by radiation from this available X-ray source. Due to its irregular shape and the relatively high density, the dolostone specimen from the Haughton impact structure was not suitable for the application of $\mu \mathrm{CT}$ scanning for this study. The scans of the shatter coned quartzite (Vredefort) and the sample in gneiss (Santa Fe) that were undertaken at LMU in Munich also encountered problems with artefacts and they were also not able to resolve the micro-fractures in the interior of the specimen.

The shatter cone sample from Serra da Cangalha was more suitable and provided better scans than the above mentioned samples showing fewer artefacts. It was, at least, possible to extract some information out of the scans. To verify the quality of the CT slices, they were compared against the corresponding thin sections (Fig. 4). There is a slight difference in the cutting plane of a slice and a corresponding thin section but this was deemed negligible for this investigative purpose. The comparison of a CT slice and thin section by superimposition revealed that major fractures were well visualized by the scan but not as good as the information provided by thin sections. Minor, subplanar fractures (Fig. 5A and B, solid black lines) partially decorated with fluid inclusion trails are not visualized in the slices (Fig. 3A and C). Equally, shock metamorphic effects cannot be visualized in the slices. Single grains are rarely identifiable in the $\mathrm{CT}$ slices, even though the resolution is far higher $(13 \mu \mathrm{m}$ per voxel) than the average grain size. The $\mu \mathrm{CT}$ scanner will only visualize differences in density contrasts, which are not given for chemically homogeneous quartz grains such as the ones that the sample from Serra da Cangalha is composed of.

Initially it was thought that it would be relatively easy to visualize the internal fracture pattern of the sample, which was tested by using the region of interest (ROI) function in the VG Studio MAX software. With a ROI operation it is possible to indicate and connect points (or areas) showing the same grey values - corresponding to the same density contrasts. Additionally, it is possible to give an upper and lower limit of (grey) values, which will be included in a ROI. Often, fractures show the same or a very similar grey value as those of the non-fractured areas. Possibly, these areas have the same density as a result of post-impact hydrothermal overprint and refill of the fractures. Thus, the ROIs either indicated almost nothing, when the range for upper and lower limit was too small, or the whole area of the ROI was indicated when the limit was chosen too high.

\section{Mineral deformation}

Our observations regarding the sample's mineralogy are generally consistent with Vasconcelos et al.'s (2013) observations on the shocked sandstone from the central uplift of the Serra da Cangalha impact structure. In particular, occurrence of syntaxial overgrowth of quartz and quartzitic cement was noted in the sample here, too. 
These authors interpreted the formation of the cement to predate the impact event as fractures related to the shatter cones cross-cut both quartz grains and cement.

Shock metamorphic effects occur predominantly at or in the vicinity of the main fractures and, thus, at or in immediate vicinity of shatter cone surfaces. However, the frequency of occurrence of shock deformation is not the same throughout the entire specimen. It appears that longitudinal sections show a higher abundance of shock metamorphic effects than transversal sections. This is probably the result of the predominant orientation of $\mathrm{PF}$, as they occur mainly sub-perpendicular to the shatter cone surface. The shatter cones are oriented with their axes subparallel to the longitudinal axis of the sample; the bedding plane is oriented at an angle of circa $35^{\circ}$ to the longitudinal axis. Longitudinal thin sections were cut subparallel to the shatter cone axes.

The occurrence of non-planar and slightly curved irregular fractures is not a diagnostic shock metamorphic effect. However, Stöffler and Langenhorst (1994) stated that their high abundance can be indicative for low shock pressures. During shock wave passage, rarefaction waves following the compression front initiate formation of such fractures (Stöffler and Langenhorst 1994). It is not clear what mineral deformation was present prior to the shock event. Thus, it cannot be completely excluded that pre-impact microdeformation could have exerted some influence on initiation and orientation of impact-derived fractures.

\section{Planar deformation features (PDF)}

Almost all observed PDF are decorated. Predominantly PDF do not penetrate entire quartz grains (Fig. 9). They usually occur in the outer parts of grains, close to grain margins. Most quartz grains affected by PDF lie directly at main fractures or in their close vicinity (less than $1 \mathrm{~mm}$ distance). Two grains containing PDF, situated ca. $3 \mathrm{~mm}$ from the shatter cone's surface, represent the largest distance of PDF from a main fracture observed in this study. When PDF do not penetrate entire grains, it is thought to indicate that they were formed at shock pressures at the lower end of the PDF formation regime (Stöffler and Langenhorst 1994). Kowitz et al. (2013b) reported experimental formation of PDF in porous sandstone at shock pressures as low as $12.5 \mathrm{GPa}$, and Huffman and Reimold (1996) discussed experimental formation of rare, single sets of PDF in Hospital Hill quartzite from the Vredefort impact structure at $8 \mathrm{GPa}$.

The irregular and inhomogeneous distribution of quartz grains displaying shock metamorphic effects next to completely unaffected grains in porous sandstone can be explained by the results of a numerical modelling study undertaken by Güldemeister et al. (2013) and petrographic studies of Kowitz et al. (2013b). These authors showed that peak shock pressures can be amplified up to four times of the nominal experimental shock pressure - in a localized area. When the initial shock wave crushes an open pore space, shock amplification is a result of a complex interaction of reflecting rarefaction and shock waves that were generated by the crushing. To the contrary, the instant closure of pores leads to a faster decay of the shock wave due to energy dissipation.

The PDF found during this study are predominantly situated at grain margins and only in small areas of the host grain. With increasing shock intensity PDF become more homogeneously distributed within the host grain until they extend over entire grains (Stöffler and Langenhorst 1994). This would also be in accordance with the highest number of PDF sets observed in a quartz host grain, of two. Grains with two sets of PDF from samples of the Serra da Cangalha central uplift have only been found in thin sections prepared from shatter cone samples (Vasconcelos et 
al. 2013; this work). The present finding of more grains with more than one set of PDF is therefore of great value for shock pressure estimations for the Serra da Cangalha impact structure. It is also in accordance with Vasconcelos et al. (2013), who proposed that the current level of exhumation corresponds to a very deep section through the Serra da Cangalha impact structure. They concluded that the peak pressure recorded outside of the collar of the central uplift does not exceed $5 \mathrm{GPa}$, but that within this ring structure, where the shatter coned sandstone was collected, the peak shock pressure was 5 to $10 \mathrm{GPa}$. Thus, most PDF in porous sandstone would only represent locally amplified peak shock pressures.

This is consistent with our observation that the measured PDF orientations are mostly (0001) and $\{10 \overline{1} 3\}$ and thus correlate with a weak to moderate shock stage (e.g., Stöffler and Langenhorst 1994; their table 5).

\section{Feather features (FF)}

A hypothesis for the genesis of FF and their relevance as a low shock-pressure indicator was discussed in French et al. (2004) and Poelchau and Kenkmann (2011). Most FF found in this study show characteristics consistent with the criteria given by Poelchau and Kenkmann (2011). However, some new findings have emerged here that imply that the definition given by Poelchau and Kenkmann (2011) may be too restrictive.

Criteria for the identification of FF given by Poelchau and Kenkmann (2011), such as maximum length of the lamellae $(\sim 10-100 \mu \mathrm{m})$, spacing of the lamellae $(1-10 \mu \mathrm{m})$, undulatory extinction relative to the host grain, and parallelism to subparallelism of the lamellae, are met by our new findings. To avoid confusion of the herein discussed FF with so-called "microscopic feather fractures" (e.g., Conrad and Friedman 1976) or Riedel shear fractures (Dresen 1991) of non-impact origin, Poelchau and Kenkmann (2011) provided criteria for the verification of FF, which have been applied here, too. Some characteristics of those so-called "microscopic feather fractures" that differentiate them from FF are: they are wedge-shaped, irregularly spaced, can be up to 10 times longer than FF, can emanate from irregular and transgranular fractures, and do not show undulatory extinction towards the host grain (Conrad and Friedman 1976; Poelchau and Kenkmann 2011).

Here, a PF with lamellae branching off from both sides is reported for the first time (Fig. 7). According to the definition of FF, lamellae emanate from one side of a PF only. FF have been interpreted as shear-induced features, with the acute angle between lamellae and PF being opened against the shear direction, based on some cases where displacement along PF was observable (Poelchau and Kenkmann 2011). Shear displacement is visible in Fig. 7 (A and C). If it is correct that the "feathers" are formed due to shear deformation, then shear movement in the case of two-sided feather arrangements must have happened at about the same time in two directions - which is physically impossible; alternatively, the PF must have been reactivated after the initial deforming movement.

According to Poelchau and Kenkmann (2011), lamellae should approximately point in the direction of the source of a shock wave. Assuming that lamellae were formed in this manner, the lamellae on the other side of the PF would have been created as the result of a wave reflected $180^{\circ}$ to the initial one. Obviously this could have happened - and because of its low probability might explain why to date only one such feature has been recorded.

A possible other explanation would be that both lamellae were created as the result of a vibrating or oscillatory movement of the fractured grain. T. Kenkmann (Freiburg, pers. comm. 2013) suggested that the occurrence of lamellae on two sides could be the result of crack branching or bifurcation, respectively. We do not 
favor this idea, as it would imply that these two-sided FF form differently from 'normal' FF. The favored explanation for this process is that it occurs as a result of vibration of the two subgrains along the PF due to scattering, reflection, interference and / or refraction of the shock wave.

A quartz grain containing four distinct curviplanar fractures (CPF) and micro-lamellae emanating from them was observed in this study. One of these curviplanar fractures shows a PF (Fig. 6E; CPF solid line) emanating from it with its own lamellae (L 1) branching off from it forming a FF. The CPF (Fig. 6E; white dashed line) is also a FF; the CPF (solid line) emanates from the lamellae-lacking side. Lamellae (L 1 and L 2) emanate equally at angles of $60^{\circ}$ from their host fractures. Both fractures indicate opposite shear senses. The CPF (solid line) could have evolved during emplacement of the CPF (dashed line) as an effect of crack bifurcation (T. Kenkmann, Freiburg, pers. comm.). Possibly, this crack even bifurcated again towards the non-lamellate side but in a non-planar manner (Fig. 6E). A CPF forming a FF and an additional FF from its non-lamellate side is contrary to Poelchau and Kenkmann's (2011) criteria for FF; i.e., FF-lamellae should only occur on one side.

A further interesting phenomenon noted here pertains to the PF in Fig. 6F. At a closer look, it is revealed that the micro-lamellae are not parallel or subparallel, some do not even touch the PF, and some appear bifurcated. The observation, that the lamellae do not touch the PF could possibly be an optical effect, as PF and lamellae are planes that are cut during thin section preparation. A bifurcation process is in accordance with the proposed (T. Kenkmann, University of Freiburg, pers. comm. 2013) bifurcation mechanism. However, it does not explain why lamellae usually only occur on one side of PF and why, sometimes, they are planar.

\section{Timing of shatter cone formation in the impact process}

The timing of the formation of shatter cones within the impact event is of major interest, as it would allow determining in which phase of shock wave passage they are created. Compressional and decompressional phases related to a propagating shock front lead to fundamentally different processes in the target rocks; i.e. have different consequences on the rocks, even though they occur extremely quickly one after the other. PDF and FF lamellae can overprint subplanar fractures within one grain. Thus, they both formed after the evolvement of subplanar fractures and PF, from which the micro-lamellae emanate. In Fig. 10 a main fracture is illustrated that displaces a set of decorated PDF, which implies that the PDF were generated prior, or at the same time, as shatter cones. The crystallographic orientation of the PDF is the same $\{10 \overline{1} 4\}$ in both parts of the fractured grain. The seemingly relatively planar main fracture; exactly where the quartz grain is displaced, cannot be considered a PF as its orientation occurs not to be crystallographically controlled (i.e., it could not be indexed). Two main fractures, opening along a PF with lamellae emanating from them and, thus, forming FF, is shown in Fig. 8A, B, C and D. This supports the suggested timing as well. The main fracture (shatter cone) must have formed after the creation of FF lamellae or simultaneously with them. PDF form after PF (Stöffler and Langenhorst 1994) but prior to FF lamellae, as lamellae overprinting PDF were observed (Poelchau and Kenkmann 2011; their figures 3A and B). Consequently, the PF was created before the main fracture / shatter cone.

Baratoux and Melosh (2003) and Sagy et al. (2004) proposed that shatter cones formed during the unloading / decompressional phase of the initial part of the shock event as tensile fractures (cf. Baratoux and Reimold 2016, 
this issue). According to French (1998), Dressler et al. (1999), Osinski and Spray (2006), Ferrière and Osinski (2010), and also Pittarello et al. (2015) findings of shatter coned clasts in crater-fill breccias imply that shatter cone formation must take place prior to crater excavation, i.e. during the compression stage of cratering. Kenkmann et al. (2012) suggested that shatter cones form after crushing of pore-volume, i.e. not before the trailing end of shock compression.

The superimposition of a shatter cone on pseudotachylitic breccia observed in the Vredefort Dome (Reimold and Colliston 1994) has been interpreted to represent shatter-coning on a pre-impact tectonic pseudotachylite (sensu strictu - friction melt) as supported by findings of such by Berlenbach and Roering (1992) and Reimold and Colliston (1994) in the northern Witwatersrand Basin and on the Vredefort Dome, respectively. If this pseudotachylitic breccia represented a melt formed during the compression/unloading phase of cratering (i.e., it represented a shock yein), this would indicate a post-compression formation of shatter cones - in the face of all other observations and opinions.

\section{Shatter cone geometry and character - Implications for their formation and orientation}

Main fractures propagate through mineral grains and around them. In close vicinity (some millimeters) of a shatter cone apex, main fractures intersecting grains are more abundant than towards the base of the shatter cone. The further away the grains are from the apex, the less frequently they are penetrated by a main fracture. Gibson and Spray (1998) found when examining shatter cone cross-sections that 'the cone surfaces are observed to propagate between mineral grains rather than through them'. Nicolaysen and Reimold (1999) observed that MSJS were meandering around grains more than cutting through them.

Johnson and Talbot (1964) suggested that shatter cones might have joined apices (forming double cones); whereby their common axis pointed into the energy release direction. During field and laboratory studies the authors, like Nicolaysen and Reimold (1999), Wieland et al. (2006), and Hasch et al. (2016, this issue), found shatter cones oriented $180^{\circ}$ to one another and pointing in many different orientations with respect to the center of the respective studied impact structures. This is in contrast to the widespread view that the apex should always point towards the source of energy release. With a closer look at the nature of shock wave propagation and interference, an attempt can be made to explain shatter cone formation. A shock wave encounters a heterogeneity or discontinuity (e.g., a pore, bedding plane, joint, fault), it crushes it, and the shock wave may become scattered, refracted, and / or reflected. If the bedding-plane or similarly well-defined (sub)planar heterogeneity represents the principal heterogeneity of the rock volume, a family of shatter cones of closely similar orientation may be created in a specific direction - as has been observed indeed at a large number of impact structures. Thus, the fact that, for example, around the Vredefort Dome's collar of supracrustal strata a principal family of upward-and-away-from-the-center pointing shatter cones was emphasized in many publications in the past is readily explained with the variation of bedding-plane orientations along the collar "line" that systematically strikes quasi-tangential around the core perimeter.

A shatter cone pointing with its apex towards the crater center can statistically be created by a second-order shock wave; however, apices can be caused to point in any direction as the new waves operate and propagate again in a spherical manner. Horsetailing can equally be explained. The shock wave encounters a discontinuity and creates 
a shatter cone. The reflected, refracted or scattered shock wave encounters new heterogeneities, whereby new shatter cones or cone segments are created. Heterogeneities (such as the conical fracture surface of a shatter cone itself) can cause the generation of a new shatter cone or horsetail structure.

Osinski and Spray (2006) found shatter cones displaying some of the above-mentioned scenarios, and presented, inter alia, photographs of nearly full $\left(360^{\circ}\right)$ shatter cones pointing with their apices in opposite directions in one specimen, or two shatter cones diverging in opposite directions and joined at their apices (their figures 5B and D). In the Tunnunik impact structure (Canada), Dewing et al. (2013) found (micro-) shatter cones or splays diverging at right angles to the striations of a host shatter cone of $\sim 3 \mathrm{~mm}$ size (Dewing et al. 2013; their figures 8D).

Shatter cone size, shape and orientation seem to be controlled by multiple factors. A major influence is the character of the inhomogeneity. During their studies of Sudbury shatter cones, Gibson and Spray (1998) found the striation amplitude to be smaller than their wavelength and connected these observations to the grain size of the affected rocks. The coarser-grained a host rock is, the larger the amplitudes and wavelengths the striations will have. The resulting cruder appearance of shatter cones, respectively their striations, is in agreement with the authors' general field observations as well as observations of many earlier authors (see e.g., Nicolaysen and Reimold 1999). But then there is the case of the Keurusselkä structure, where quite intricately formed, decimeter-sized shatter cones are observed in medium- to coarse-grained, even pegmatoidal granitoids (Hasch et al. 2016, this issue).

As already stated, in close vicinity of a shatter cone's apex, the orientation of fractures is not controlled by mineral grain margins or other areas of weakness, but by the shape of the shatter cone itself. Fractures further away from the shatter cone's apex predominantly run around grain margins. The formation of these fractures seems to have been (locally) controlled by areas of weakness or density contrasts, such as grain margins; the fracturing process is rather inter- than intragranular. Hence, the mineral grain-penetrative character of the shatter cone's surface fracture is a function of its distance to the apex. Sagy et al. (2004) stated, in agreement with the authors' observations, that striations can be observed down to almost the grain size of the hosting lithology. It is, however, not clear yet - and also not resolved in this $\mu \mathrm{CT}$ study - what the nature and cause of the striations are.

As most researchers agree that shatter cones develop when shock fronts encounter heterogeneities, it could be possible to generate a shatter cone at very low initial shock pressure of less than one GPa, as the result of shock pressure amplification - as suggested by Güldemeister et al. (2013) and Kowitz et al. (2013b) - on a crushed pore. The crushed pore would in this case serve to amplify the shock intensity and also as the heterogeneity, from which the shatter cone propagates.

\section{Termination of shatter cones by fractures}

It appears that the termination of shatter cones, i.e., the most distant point from the apex, is generally related to the presence of fractures or joints (e.g., bedding planes or bedding-parallel fractures, graded bedding). These heterogeneities, mainly joints or lithological contrasts occurring in recurring sets, each of the sets has joints oriented in a subparallel arrangement (cf. Crósta et al. 2012; their figure 13 C). The angles under which these joints are oriented to each other are not systematic. If only one inhomogeneity (joint or fracture) is present, it can serve to limit the growth of a shatter cone. The only definite statement that can be made regarding the timing of the formation of 
these sets of joints is that they must evolve prior or simultaneous to the shatter cone's fracture. Otherwise the joints would not be able to control the shatter cone's shape and size. It is also still to be determined whether (all of?) the pre-shatter coning fractures are caused by the impact event itself (during compression) - or already existed prior to it.

\section{CONCLUSIONS AND RECOMMENDATIONS}

\section{Micro-computed tomography}

Unfortunately, the first attempt at micro-CT visualization of the innards of shatter cones was not overly successful because we were not able to resolve the interior (micro-)fracture pattern as we had aimed for. However, micro-computed tomography is a useful tool to visualize shatter cone surfaces. To obtain scans of shatter cones with a higher resolution and contrast than those obtained during this study, the utilization of a $\mu \mathrm{CT}$ or nCT scanner with an X-ray tube capable to produce a very energetic X-ray beam would be desirable. Thus, it would be possible to better visualize small changes in material density and micrometer to sub-micrometer fractures. However, such a CT scanner could also amplify inherent problems. The greater ability of high-energy X-rays to penetrate dense material, compared to low-energy X-rays, also results in a loss of sensitivity to low-density contrasts and changes in composition (e.g., Ketcham and Carlson 2001). A very high energetic X-ray beam could therefore obscure small features, such as micro-fractures possibly related to shatter cone surface striations.

As the investigated, likely > 250 Ma old sample from Serra da Cangalha was subjected to post-impact overprinting, micro-cracks/fractures were "healed" and their visualization in $\mu$ CT images was not possible. A possibility to overcome this problem would be to utilize 'fresh' samples, such as small shatter cones produced experimentally.

The utilization of synchrotron X-ray tomography instead of a $\mu \mathrm{CT}$ might better visualize a shatter cone's interior micro-fracture pattern. The quality of synchrotron X-ray tomography scans is generally superior to $\mu \mathrm{CT}$ with regard to detection of detail, sharpness, and spatial and contrast resolution; and it might even generate less artefacts (Kastner et al. 2010). However, as the aim of the study was to test $\mu \mathrm{CT}$, this option was beyond the scope of this study.

Another step forward in the application of $\mu \mathrm{CT}$ for studying micro-fracture patterns in shatter cones could be the utilization of the latest $\mu$ CT scanners that are available on the market (Nanotem $\mu$ CT scanners, from XRadia, SkyScan and FEI, inter alia). These scanners are able to provide higher resolution images, create X-ray beams with higher energy and have improved automated software for reconstruction of the datasets.

\section{Petrographic analysis}

The petrographic study of thin sections of the shatter coned sandstone sample from Serra da Cangalha yielded new insights, and provided further constraints on the timing of the formation of shatter cones during the late compression phase of cratering. Multiple variations of FF, not described before, were found and the processes leading to their formation have been discussed. It has been affirmed, as previously discussed by other authors, that 
shatter cone orientation is versatile and does not necessarily need to be oriented with apices pointing towards the point of impact. With distance from the apex, main fractures (or shatter cone surfaces) become more inter- than intragranular. It is also noted that shatter cone sizes are limited by sets of fractures/joints.

To summarize, the main characteristics and general observations on shatter cones, derived from this study in comparison with the literature, are compiled in Table 1.

\section{Table 1}

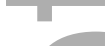

Table 1

PF occur more often in close vicinity of shatter cone surfaces than further away or directly at main fractures; their preferred orientation to the main fracture is mostly near-perpendicular, but tangential orientations or others at acute angles to the surface have also frequently been observed. PF can be displaced and separated by the shatter cone surface. The measured PF orientations are mostly $\{10 \overline{1} 1\}$ and $\{10 \overline{1} 3\}$.

PDF occur in the study specimen at a maximum of two sets per grain; they predominantly do occur only in small areas of the host grains, preferably along grain margins. Only in rare cases were penetrative PDF noted. The PDF bearing grains are usually situated directly at main fractures. PDF can be displaced by main fractures and, thus, evolve before them or at the same time. In the latter case, the (displaced) PDF orientation was measured at $\{10 \overline{1} 4\}$. In general the indexed PDF suggest a rather weak to moderate shock setting.

The definition of FF after Poelchau and Kenkmann (2011) does not account for all the types of FF observed during this study. FF were previously defined to have lamellae only on one side of a PF. Two-sided FF or truly 'feather-like' FF (Fig. 7) were not known. While this phenomenon may occur very rarely, the mechanisms of formation of FF as shear-induced features, as proposed previously, cannot explain this case. The favored hypothesis for the formation of this specific case is that 'arrowhead-like' FF occur as the result of oscillation of both subgrains in the course of scattering, refraction, and / or reflection of the shock wave. Curviplanar and curved fractures (Fig. $6 \mathrm{~B}$ and $\mathrm{C}$ ) as the plane from which lamellae emanate to form FF were also not included in the original FF definition; however, their involvement can be explained with this hypothesis as well. As suggested by T. Kenkmann (University of Freiburg, pers. comm., 2013; also Kenkmann et al. 2016, this issue), bifurcation processes may play a role, too. A FF with 'poorly developed' lamellae (or micro-fractures) emanating from one side of a PF, whereby the lamellae are not parallel or subparallel and even ramify or bifurcate (Fig. 6F), was detected, too.

Information pertaining to constraints on the time of emplacement of shatter cones obtained during this study is summarized in Table 2.

Table 2

This table (Table 2) demonstrates that shatter cones form at or before the excavation stage of impact, simultaneously with or after the closure of porosity, the emplacement of PF, subplanar fractures and FF lamellae, and at the same time or prior to PDF formation. Thus, the earliest possible time of formation of shatter cones is during the late compressional phase of shock wave passage. 


\section{ACKNOWLEDGEMENTS}

We would like to particularly thank Álvaro Crósta and Marcos Vasconcelos for making the sample from Serra da Cangalha available to us. Thanks are also due to Astrid Kowitz and Thomas Kenkmann for fruitful discussions on micro-deformation features and shock waves. We greatly thank Elmar Buchner (Neu-Ulm) for providing a shatter cone in gneiss from the Santa Fe impact structure (USA) for $\mu \mathrm{CT}$ scanning. We would also like to thank Stefan Moser (Fraunhofer Ernst-Mach-Institut für Kurzzeitdynamik, Freiburg) for his efforts to scan other shatter coned samples, and Kai-Uwe Hess and Kate Dobson (Ludwig-Maximilians-Universität, München) for their efforts to scan two samples. Additionally we would like to thank C. Cavaré-Hester (Université Paul Sabatier, Toulouse III, Observatoire Midi-Pyrénées) for the preparation of high resolution flatbed scans of some of the thin sections. W.U.R.'s research is supported by the DFG (Deutsche Forschungsgemeinschaft) and the Museum für Naturkunde Berlin. The part of this work carried out at MfN constituted the Diploma Thesis of P.T.Z. Finally, we would like to state our appreciation of the input from three reviewers - Lidia Pittarello, Carl Alwmark, and one anonymous reviewer - and the Guest Editor, David Baratoux. Their detailed efforts resulted in significant improvement of our manuscript.

\section{REFERENCES}

Baratoux D. and Melosh H. J. 2003. The formation of shatter cones by shock wave interference during impacting. Earth and Planetary Science Letters 216: 43-54. doi: 10.1016/S0012-821X(03)00474-6.

Baratoux D., Bouley S., Reimold W. U. and Baratoux L. 2014. The first three dimensional model of shatter cones (abstract). 77th Annual Meteoritical Society Meeting, \#5020.

Baratoux D. and Reimold W. U. 2016. The Current State of Knowledge about Shatter Cones: Introduction to the Special Issue. Meteoritics and Planetary Science, this issue.

Baratoux D., Bouley S., Reimold W. U. and Baratoux L. 2016. Morphometric analysis and classification of the threedimensional geometry of shatter cones. Meteoritics and Planetary Science, this issue. gems

Berlenbach J. W. and Roering C. 1992. Sheath-fold-like structures in pseudotachylytes. Journal of Structural Geology 14: 847-856. doi: 10.1016/0191-8141(92)90045-X.

Branco W. and Fraas E. 1905. Das kryptovulkanische Becken von Steinheim. Königlich-Preußische Akademie der Wissenschaften. Verlag G. Reimer, Berlin. 64 pp.

Conrad R. E. and Friedman M.1976. Microscopic feather fractures in the faulting process. Tectonophysics 33: 187198. doi: 10.1016/0040-1951(76)90056-1. 
Crósta A. P., Kazzuo-Vieira C., Pittarello L., Koeberl C. and Kenkmann T. 2012.Geology and impact features of Vargeão Dome, southern Brazil. Meteoritics and Planetary Science 47:51-71. doi: 10.1111/j.1945-

5100.2011.01312.x.

Dawson E. 2009. Meteorite impact shatter cones - adiabatic shear bands? DYMAT, 9th International Conference on the Mechanical and Physical Behaviour of Materials under Dynamic Loading. Les Ulis, France, EDP Sciences. 1471-1477. doi: 10.1051/dymat/2009208.

Deutsch A., Poelchau M. H. and Kenkmann T. 2015. Impact metamorphism in terrestrial and experimental cratering events. In: Lee M. R, and Leroux H. (Eds.), Planetary Mineralogy. EMU Notes in Mineralogy 15. London, pp. 89127.

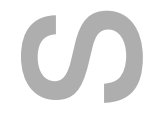

Dietz R. S. 1947. Meteorite impact suggested by the orientation of shatter cones at the Kentland disturbance. Science 105: 42-43. doi: 10.1126/science.105.2715.42.

Dietz R. S. 1960. Meteorite impact suggested by shatter cones in rock. Science 131: 1781-1784. doi: 10.1126/science.131.3416.1781.

Dresen G. 1991. Stress distribution and the orientation of Riedel shears. Tectonophysics 188: 239-247. doi: 10.1016/0040-1951(91)90458-5.

Dressler B. O., Sharpton V. L. and Copeland P. 1999. Slate Islands, Lake Superior, Canada: A mid-size, complex impact structure. Geological Society of America Special Papers 339: 109-124. doi: 10.1130/0-8137-2339-6.109.

Engelhardt W. v. and Bertsch W. 1969. Shock induced planar deformation structures in quartz from the Ries crater, Germany. Contributions to Mineralogy and Petrology 20: 203-234. doi: 10.1007/BF00377477.

Ferrière L., Morrow J. R., Amgaa T. and Koeberl C. 2009. Systematic study of universal-stage measurements of planar deformation features in shocked quartz: Implications for statistical significance and representation of results. Meteoritics and Planetary Science 44: 925-940. doi: 10.1111/j.1945-5100.2009.tb00778.x.

Ferrière L. and Osinski G. R. 2010. Shatter cones and associated shock-induced microdeformations in minerals New investigations and implications for their formation (abstract). 41 st Lunar and Planetary Science Conference. LPI Contribution 1533, \#1392, 2pp. 
Ferrière L., Raiskila S., Osiniski G. R., Pesonen L. J. and Lehtinen M. 2010. The Keurusselkä structure, Finland Impact origin confirmed by characterization of planar deformation features in quartz grains. Meteoritics and Planetary Science 45: 434-446. doi: 10.1111/j.1945-5100.2010.01032.x.

Ferrière L., Brandstätter F. and Koeberl C. 2013. Finding Shatter Cones in Meteorites from the Natural History Museum Vienna Collection (abstract). 76th Annual Meteoritical Society Meeting. \#5193.

French B. M. 1998. Traces of Catastrophe: A Handbook of Shock-Metamorphic Effects in Terrestrial Meteorite Impact Structures. LPI Contribution, 954, Lunar and Planetary Institute, Houston. 120 pp.

French B. M. and Koeberl C. 2010. The convincing identification of terrestrial meteorite impact structures: What works, what doesn't, and why. Earth-Science Reviews 98: 23-170. doi: 10.1016/j.earscirev.2009.10.009.

Gash P. J. S. 1971. Dynamic Mechanism for the Formation of Shatter Cones. Nature Physical Science 230: 32-35. doi: 10.1038/physci230032a0.

Gay N. C. 1976. Spherules on shatter cone surfaces from the Vredefort Structure. Science 194: 724-725. doi: 10.1126/science.194.4266.724.

Gay N. C., Comins N. R. and Simpson C. 1978. The composition of spherules and other features on shatter cone surfaces from the Vredefort structure, South Africa. Earth and Planetary Science Letters 41: 372-380. doi: $10.1016 / 0012-821 X(78) 90192-9$.

Gibson H. M. and Spray J. G. 1997. Diagnostic criteria for the recognition of shatter cones (abstract). Large Meteorite Impacts and Planetary Evolution. Sudbury 97. LPI Contribution, Lunar and Planetary Institute, Houston. \#922: 16-17. http://www.lpi.usra.edu/meetings/impacts97/pdf/6032.pdf.

Gibson H. M. and Spray J. G. 1998. Shock-induced melting and vaporization of shatter cone surfaces: Evidence from the Sudbury impact structure. Meteoritics and Planetary Science 33: 329-336. doi: 10.1111/j.1945-

5100.1998.tb01637.x.

Gibson R. L. and Reimold W. U. 2008. Geology of the Vredefort Impact Structure: A Guide to Sites of Interest. Memoir 97, Council for Geoscience, Pretoria, RSA, 181 pp.

Grieve R. A. F., Langenhorst F. and Stöffler D. 1996. Shock metamorphism of quartz in nature and experiment: II. Significance in geoscience. Meteoritics and Planetary Science 31: 6-35. doi: 10.1111/j.1945-5100.1996.tb02049.x. 
Güldemeister N., Wünnemann K., Durr N. and Hiermaier S. 2013. Propagation of impact-induced shock waves in porous sandstone using mesoscale modeling. Meteoritics and Planetary Science 48: 115-133. doi: 10.1111/j.19455100.2012.01430.x.

Hasch M., Reimold W. U., Raschke U. and Zaag P. T. 2016. Shatter cones at the Keurusselkä impact structure and their relation to local jointing. Meteoritics and Planetary Science, this issue.

Hietala S. and Moilanen J. 2004. Keurusselkä - A new impact structure in central Finland (abstract). 35th Lunar and Planetary Science Conference. \#1619. CD-ROM.

Huber M. S., Ferrière L., Losiak A. and Koeberl C. 2011.ANIE: A mathematical algorithm for automated indexing of planar deformation features in quartz grains. Meteoritics and Planetary Science 46: 1418-1424. doi:

10.1111/j.1945-5100.2011.01234.x.

Hubbell J. H. and Seltzer S. M. 1995. Tables of X-ray Mass Attenuation Coefficients and Mass Energy-Absorption Coefficients $1 \mathrm{keV}$ to 20MeV for Elements $Z=1$ to 92 and 48 Additional Substances of dosimetric interest. NISTIR 5632, National Institute of Standards and Technology, Gaithersburg, MD, USA.

http://www.nist.gov/pml/data/xraycoef/index.cfm.

Huffman A. R. and Reimold W. U. 1996. Experimental constraints on shock-induced microstructures in naturally deformed silicates. Tectonophysics 256: 165-217. doi: 10.1016/0040-1951(95)00162-X.

Johnson G. P. and Talbot R. J. 1964. A theoretical study of the shock wave origin of shatter cones. M.Sc. Thesis. Air Force Institute of Technology, Wright-Patterson Airforce Base, Dayton, Ohio, USA. 103 pp.

Kastner J., Harrer B., Requena G. and Brunke O. 2010. A comparative study of high resolution cone beam X-ray tomography and synchrotron tomography applied to Fe- and Al-alloys. NDT \& E International 43: 599-605. doi: 10.1016/j.ndteint.2010.06.004.

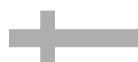

Kenkmann T, Reimold W. U., Khirfan M., Salameh E., Khoury H. and Konsul K. 2010. The complex impact crater Jebel Waqf as Suwwan in Jordan: Effects of target heterogeneity and impact obliquity on central uplift formation. In: Gibson R. L. and Reimold W. U. (Eds.), Large Meteorite Impacts and Planetary Evolution IV. Geological Society of America Special Papers 465: 471-487. doi: 10.1130/2010.2465(23).

Kenkmann T., Crósta A. P. and Reimold W. U. 2011. The complex impact structure Serra da Cangalha, Tocantins State, Brazil. Meteoritics and Planetary Science 46: 875-889. doi: 10.1111/j.1945-5100.2011.01199.x. 
Kenkmann T., Poelchau M. H., Trullenque G., Hoerth T., Schäfer F., Thoma K. and Deutsch A. 2012. Shatter cones formed in a MEMIN impact cratering experiment (abstract). 75th Annual Meeting of the Meteoritical Society Meeting. \#5092. http://www.lpi.usra.edu/meetings/metsoc2012/pdf/5092.pdf.

Kenkmann T., Hergarten S., Kuhn T. and Wilk J. 2016. Formation of shatter cones by symmetric crack bifurcation: Phenomenological modeling and validation. Meteoritics and Planetary Science, this issue.

Ketcham R. A. and Carlson W. D. 2001. Acquisition, optimization and interpretation of X-ray computed tomographic imagery: applications to the geosciences. Computers and Geosciences 27: 381-400. doi: 10.1016/S0098-3004(00)00116-3.

Kowitz A., Schmitt R. T., Reimold W. U. and Hornemann U. 2013a. The first MEMIN shock recovery experiments at low shock pressure (5-12.5 GPa) with dry, porous sandstone. Meteoritics and Planetary Science 48: 99-114. doi: 10.1111/maps.12030.

Kowitz A., Güldemeister N., Reimold W. U., Schmitt R. T. and Wünnemann K. 2013b. Diaplectic quartz glass and $\mathrm{SiO}_{2}$ melt experimentally generated at only $5 \mathrm{GPa}$ shock pressure in porous sandstone: Laboratory observations and meso-scale numerical modeling. Earth and Planetary Science Letters 384: 17-26. doi: 10.1016/j.epsl.2013.09.021.

Langenhorst F. and Deutsch A. 1994. Shock experiments on pre-heated $\alpha$ - and $\beta$-quartz: I. Optical and density data. Earth and Planetary Science Letters 125: 407-420. doi: 10.1016/0012-821X(94)90229-1.

Losiak A. Golebiowska I., Ferrière L., Wojciechowski J., Huber M. S. and Koeberl C. 2016. WIP: A Web-based program for indexing planar features in quartz grains and its usage. Meteoritics and Planetary Science. doi:

$10.1111 /$ maps. 12614 .

Lespinasse M. 1999. Are fluid inclusion planes useful in structural geology? Journal of Structural Geology 21: 12371243. doi: 10.1016/S0191-8141(99)00027-9.

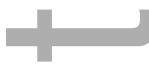

Long H., Swennen R., Foubert A., Dierick M. and Jacobs P. 2009. 3D quantification of mineral components and porosity distribution in Westphalian C sandstone by microfocus X-ray computed tomography. Sedimentary Geology 220: 116-125. doi: 10.1016/j.sedgeo.2009.07.003.

Manton M. I. 1965. The orientation and origin of shatter cones in the Vredefort Ring. In: Geological Problems in Lunar Research. New York Academy of Science Annals 123: 1017-1049. doi: 10.1111/j.1749-6632.1965.tb20415.x.

McHone J. F., Shoemaker C., Killgore M. and Killgore K. 2012. Shatter Cones in Meteorites (abstract). 75th Annual Meteoritical Society Meeting. \#5393.

This article is protected by copyright. All rights reserved 
Mees F., Swennen R., Van Geet M. and Jacobs P. 2003. Applications of X-ray computed tomography in the geosciences. Geological Society, London, Special Publications 215: 1-6. doi: 10.1144/GSL.SP.2003.215.01.01.

Milton D. J. 1977. Shatter cones - An outstanding problem in shock mechanics. In: Roddy D. J., Pepin R. O. and Merrill R. B. (Eds.), Impact and Explosion Cratering. Planetary and Terrestrial Implications. Pergamon Press, New York, pp. 703-714.

-

Mohr-Westheide T. and Reimold W. U. 2010. Formation of pseudotachylitic breccias in the central uplifts of very large impact structures: Scaling the melt formation. Meteoritics and Planetary Science 46: 543-555. doi: 10.1111/j.1945-5100.2011.01173.x.

Mutina A. and Koroteev D. 2012. Using X-Ray Microtomography for the Three Dimensional Mapping of Minerals. Microscopy and Analysis 26: 7-123 (EU).

Nicolaysen L. O. and Reimold W. U. 1999. Vredefort shatter cones revisited. Journal of Geophysical Research 104: 4911-4930. doi: 10.1029/1998JB900068.

Osinski G. R. and Spray J. G. 2006. Shatter cones of the Haughton impact structure, Canada. Proceedings of the 1st International Conference on Impact Cratering in the Solar System, European Space Agency Special Publication SP612 (CD-ROM). pp. 95-99.

Pettijohn F. J. 1975. Sedimentary Rocks. Third Edition. Harper and Row, New York. 628 pp.

Poelchau M. H. and Kenkmann T. 2011. Feather features: A low shock pressure indicator in quartz. Journal of Geophysical Research, B02201, 13 pp. doi: 10.1029/2010JB007803.

Pittarello L., Nestola F., Viti C., Crósta A. P. and Koeberl C. 2015. Melting and cataclastic features in shatter cones in basalt from the Vista Alegre impact structure, Brazil. Meteoritics and Planetary Science 50: 1228-1243. doi: 10.1111/maps.12466,

Reimold W. U. and Colliston W. P. 1994. Pseudotachylites of the Vredefort Dome and the surrounding Witwatersrand Basin, South Africa. In: Dressler B. O., Grieve R. A. F. and Sharpton V. L. (Eds.), Large Meteorite Impacts and Planetary Evolution. Geological Society of America Special Paper 293: 177-196. doi: 10.1130/SPE293p177.

Reimold W. U. and Koeberl C. 2014. Impact structures in Africa: A review. Journal of African Earth Sciences 93 : 57-175. doi: 10.1016/j.jafrearsci.2014.01.008. 
Reimold W. U., Ferrière L., Deutsch A. and Koeberl C. 2014. Impact controversies: Impact recognition criteria and related issues. Meteoritics and Planetary Science 49: 723-731. doi: 10.1111/maps.12284.

Robertson P. B. and Mason G. D. 1975. Shatter cones from Haughton Dome, Devon Island, Canada. Nature 255, 393-394 doi: 10.1038/255393a0.

Roddy D. J. and Davis L. K. 1977. Shatter cones formed in large scale experimental explosion craters. In: Roddy D. J., Pepin R. O. and Merrill R. B. (Eds.), Impact and Explosion Cratering. Planetary and Terrestrial Implications. Pergamon Press, New York, pp. 715-750.

Roedder E. 1984. Fluid inclusions. In: Reviews in Mineralogy 12. Mineralogical Society of America. Washington DC. 71-77.

Sagy A., Fineberg J. and Reches Z. 2004. Shatter cones: Branched, rapid fractures formed by shock impact. Journal of Geophysical Research 109, B10209, 20 pp. doi: 10.1029/2004JB003016.

Schneider E. and Wagner G. A. 1976. Shatter cones produced experimentally by impacts in limestone targets. Earth and Planetary Science Letters 32: 40-44. doi: 10.1016/0012-821X(76)90182-5.

Stöffler D. 1971. Coesite and stishovite in shocked crystalline rocks. Journal of Geophysical Research 76: 54745488. doi: 10.1029/JB076i023p05474.

Stöffler D. and Langenhorst F. 1994. Shock metamorphism of quartz in nature and experiment: I. Basic observation and theory. Meteoritics and Planetary Science 29: 155-181. doi: 10.1111/j.1945-5100.1994.tb00670.x.

Trepmann C. A. 2008. Shock effects in quartz: Compression versus shear deformation - An example from the Rochechouart impact structure, France. Earth and Planetary Science Letters 267: 322-332. doi:

10.1016/j.epsl.2007.11.035.

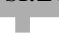

Vasconcelos M. A. R., Crósta A. P., Reimold W. U., Góes A. M., Kenkmann T. and Poelchau M. H. 2013. The Serra da Cangalha impact structure, Brazil: Geological, stratigraphic and petrographic aspects of a recently confirmed impact structure. Journal of South American Earth Sciences. 15 pp. doi: 10.1016/j.jsames.2013.03.007.

Wieland F. 2007. Structural analysis of impact-related deformation in the collar of the Vredefort Dome, South Africa. Ph.D. Thesis. School of Geosciences, University of Witwatersrand, Johannesburg, Gauteng, RSA, pp. 344. http://hdl.handle.net/10539/5748. 
Wieland F., Reimold W. U. and Gibson R. L. 2006. New observations on shatter cones in the Vredefort impact structure, South Africa, and evaluation of current hypotheses for shatter cone formation. Meteoritics and Planetary Science 41: 1737-1759. doi: 10.1111/j.1945-5100.2006.tb00449.x.

Wilk J. and Kenkmann T. 2015. The Surface Structure of Shatter Cones in Experimental Impact Craters (abstract). 46th Lunar and Planetary Science Conference. LPI Contribution 1832: \#2637, 2 pp.

Wilk J. and Kenkmann T. 2016. Formation of shatter cones in MEMIN impact experiments. Meteoritics and Planetary Science, this issue.

Zaag P. T. 2013. Petrographic and $\mu$-computed tomography investigations of shatter cones. Diploma Thesis. Freie Universität Berlin and Museum für Naturkunde Berlin, Berlin, Germany, 103pp. (unpublished).

Zaag P. T. 2014. Geological mapping in the Witwatersrand Supergroup of the northwestern collar of the Vredefort Dome - including an investigation of the orientation of shatter cones. Diploma Mapping Thesis. Freie Universität Berlin and Museum für Naturkunde Berlin, Berlin, Germany. 118pp. (unpublished).

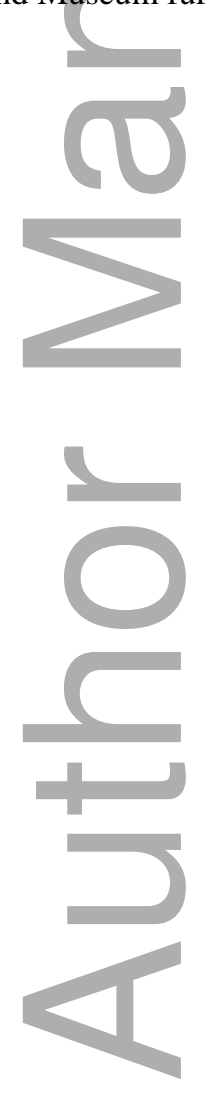




\section{CAPTIONS}

Fig. 1: (A) shows a fine development of a nearly complete shatter cone with intricate striations in dolostone from the Haughton impact structure (Canada). The shatter cone (of ca. $140^{\circ}$ curvature) shows a narrow apical angle; but from there, it quickly fans out as the radiating striations diverge away from the down pointing apex. The specimen is from the private collection of W. U. Reimold (obtained courtesy of B. O. Dressler, Vancouver Island, Canada). (B) shows a simplified sketch of the cone in (A), illustrating the main features of a shatter cone: (a) the two outermost striations delimiting the cone's lateral terminations and (a-a) encloses the apical angle; (b) the lower termination of the cone; (c) is a single striation, whereas (d) shows branching striations, i.e. traditionally known as horsetailing; and (e) the height or "size" of the cone, i.e., the maximum distance between apex and base termination of the shatter cone. (C) shows a rotated (counter clockwise) and enlarged portion of (A); note the horsetailing as described for (d).

Fig. 2: Four images (top row) of the 3D volume graphic of the analyzed specimen from Serra da Cangalha in an arbitrary $x, y, z$ coordinate system, illustrating the specimen in 3D. The images illustrate the good resolution of the surface scan. Two shatter cone segments are illustrated in front view, with clearly visible fine striations and downward pointing apices. Four shatter cone segments point in the $+180^{\circ}$ view opposite to those shown in the $0^{\circ}$ image. For better visualization of the striations and the apical areas of the four segments, enlarged images of the + $180^{\circ}$ and $0^{\circ}$ scenes (rotated $90^{\circ}$ clockwise) are shown in the two bottom rows. The orientations of the apices are highlighted (white arrows). Note the differences in the grey value of the top quarter of the scan; they were created during the reconstruction process and could not be eliminated. Shades were created during the visualization process of the 3D volume. The sample measures $6.5 \mathrm{~cm}$ in height.

Fig. 3: Image of a CT slice (2D $\mu \mathrm{CT}$ cross-sectional image) by itself (A), and almost perfectly superimposed onto the corresponding thin section scan (C). Image (B) shows the same thin section scan by itself. The CT slice and the thin section were created/cut parallel to the Y-X plane (transversal sections) of the shatter cone; i.e., they are oriented (sub)perpendicular to the elongated axis of the shatter cone(s) and their striations. (A) Note the $\sim$ NE to SW and NW to SE trending main fractures (black, curvilinear lines) describing the 'surface' of a shatter cone. Black and white (light) areas, within the sample, represent places of anomalous density, pores and fractures. Some remnants from image processing are visible (black areas 'outside' of the slice (A and C)).

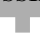

Fig. 4: Three images of the same area of the shatter cone sample in an arbitrary $x ; y ; z$ coordinate system. The ellipses indicate the position of a void. Image (A) shows a cropped 3D volume. (B) shows a cropped area of the corresponding 2D slice, and (C) the corresponding thin section. The size of the images (A, B and C), and the cropped areas are not exactly the same.

Fig. 5: One of the transversal thin sections that were created parallel to the $\mathrm{Y}-\mathrm{X}$ plane of the shatter cone. (A) The entire scan of the thin section (transversal with respect to the long-axis of the shatter cones), simply created with a flatbed scanner. The shatter cone surfaces are indicated with black dashed lines; they surround and transect almost 
the entire thin section. Black solid lines (A) and white solid lines (B) indicate important orientations of subplanar fractures and fluid inclusion trails (FIT). (B) An enlarged portion of (A), as indicated with a black square; the image is derived from a mosaic of 12 microphotographs. Contrast of the image has been increased for better visualization. Note the linear arrangements of subplanar fractures penetrating almost the entire thin section. They are limited by the shatter cone surfaces.

Fig. 6: (A) Microphotograph illustrating a typical feather feature (FF). The photo shows a quartz grain with two NW to SE trending PF. One PF intersects the entire grain - note displacement (top left and bottom right) by a few micrometers. A whole FF (in the dashed ellipse) comprises a PF (long line) and parallel lamellae (micro-fractures, six short lines) branching off at an angle of $\sim 70^{\circ}$. The PF is oriented parallel to $\{10 \overline{1} 1\}$, the lamellae are oriented at $\{51 \overline{6} 0\}$. (B) A curviplanar fracture that trends NW-SE and has lamellae at an angle of $40^{\circ}$. (C) A FF consisting of a curved fracture trending SW-NE (black dashed line) and lamellae at angles of about $50^{\circ}$ to the 'quill'. Note that the curved fracture is displaced by a curviplanar fracture (white dashed line); however, at the grain scale no displacement could be observed. Images B and C were taken in plane polarized light. (D) A main fracture splits running around the top and bottom of the quartz grain in the central area of the picture and then reunites to the right of the field of view. Subplanar fractures (partially healed to fluid inclusion trails) are abundant; in this part of the section these fractures are predominantly oriented at about $85^{\circ}$ to the E-W trending main fracture. Four slightly curved PF with lamellae (FF) oriented more or less parallel to each other in a single quartz grain. The area of image $\mathrm{E}$ is indicated by a white rectangle in D. (E) A curviplanar fracture (CPF; white, dashed line) with lamellae (L 2) emanating at an angle of $\sim 60^{\circ}$, indicating a sinistral shear sense. In contrast, a short CPF (solid line) with lamellae (L 1) emanating equally at $\sim 60^{\circ}$ indicates a dextral shear sense. The CPF (solid line) is $40 \mu \mathrm{m}$ long and emanates at an angle of $45^{\circ}$ to the lamellae-free side of the curviplanar fracture. (F) Microphotograph of a quartz grain intersected and slightly displaced by a PF. On the lower side of the PF occur micro-fractures (L), at different angles. The micro-fractures are not parallel to each other. Note that the lamellae are seemingly not attached to the PF and some may even be bifurcated. See text for discussion. Images (A-F) were taken under crossed polarizers.

Fig. 7: Three microphotographs of the same quartz grain, taken in plane polarized light, at different magnifications (A, B); the magnification of (C) is slightly larger than in (B). The quartz grain is intersected by two PF; the upper one (PF 1) shows lamellae (L 1, L 2) on both sides of the PF forming an arrowhead-like FF (A, B, C). PF 2 does not intersect the entire grain; it shows lamellae (L 3) on one side (A, C). For convenience PF 1 and 2 are indicated in all three images. (B) shows the same FF at a higher magnification. The lamellae on both sides of PF 1 form angles of $~$ $45^{\circ}$ (B). (C) enhances the $\sim 10 \mu \mathrm{m}$ long displacement along PF 1 (top left, top right). PF 1 is oriented at (0001), L 1 $\{11 \overline{2} 1\}$ and $\mathrm{L} 2\{10 \overline{1} 1\}$.

Fig. 8: Microphotographs of some quartz grains and small chert fragments in plane polarized light (A, C and D) and under crossed polarizers (B). (A) shows the orientation of the main fracture (dashed line) and the thin sections margin (top left). The white rectangle in (B) shows the area of (C). (B) The black line from $\mathrm{E}$ to $\mathrm{W}$ is a main fracture showing displacement and separation (dashed line in (A)). PF 3 is oriented parallel to $\{10 \overline{1} 1\}$. Along the main 
fracture occurs a FF (L 1, short black lines) with the inherent PF 1 (white line) oriented parallel to it (B and C). Another FF (running NNE-SSW, black line denoted PF 2), with its lamellae (L 2, short black lines) pointing in the same direction as the one along the main fracture but in a different quartz grain, is visible in (C). (D) A different FF; in another thin section, which is equally displaced by a main fracture. A subplanar fracture (SF) is overprinted by FF lamellae. Crystallographic orientations of the micro structures are given in the images (B, C and D).

Fig. 9: All four photos were taken in plane polarized light. (A) shows a microphotograph of a fractured quartz grain with two sets of PDF, the orientations of which are indicated (both parts of the fractured grain become extinct in the same position under crossed polarizers). The PDF are oriented at $\{11 \overline{2} 1\}$ and (0001). Image (B) shows some quartz, one is intersected by a FF, the PF is oriented at (0001), the lamellae at $\{10 \overline{1} 1\}$. The position of image (C) is indicated (black rectangle) in (B). (C) The PDF are oriented at (0001) and $\{10 \overline{1} 3\}$, they are not considered to represent two sets in one grain. However, the c-axis of the quartz grains containing (0001) oriented PDF is equally oriented. (D) shows one quartz grain containing a poorly developed FF and a set of marginally situated PDF (oriented (0001)).

Fig. 10: (A) shows a horizontally trending main fracture. (B) shows a close-up of the area indicated by a white rectangle in (A). Note that the NE-SW trending set of decorated PDF (orientation enhanced by a black and white line) is displaced by about $70 \mu \mathrm{m}$ by the main fracture representing a shatter cone surface that must clearly post-date the formation of PDF. The crystallographic orientations of both sets of PDF in the two parts of the fractured host grain are equal $\{10 \overline{1} 4\}$.

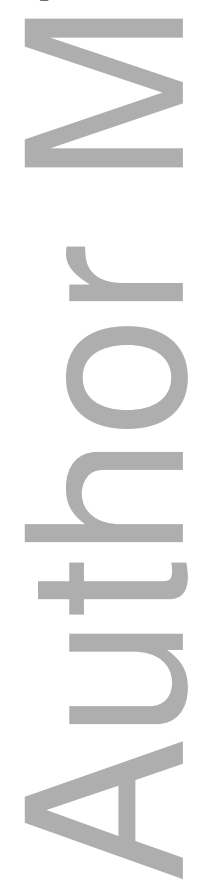


Table 1: Facts, characteristics and findings of probable relevance for the formation of shatter cones (SC). Compiled based on the references given in this paper, and observations from this study.

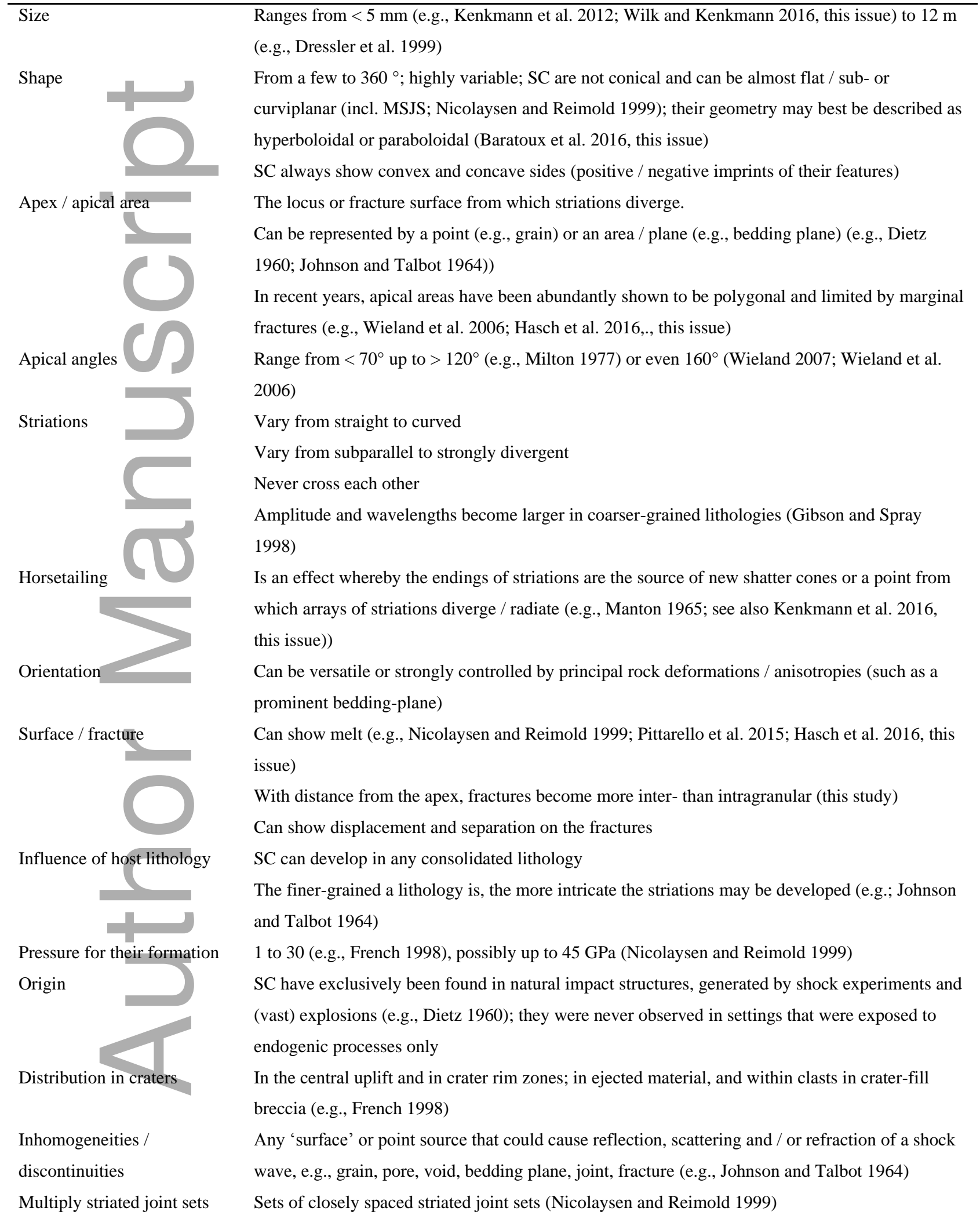

(MSJS) 


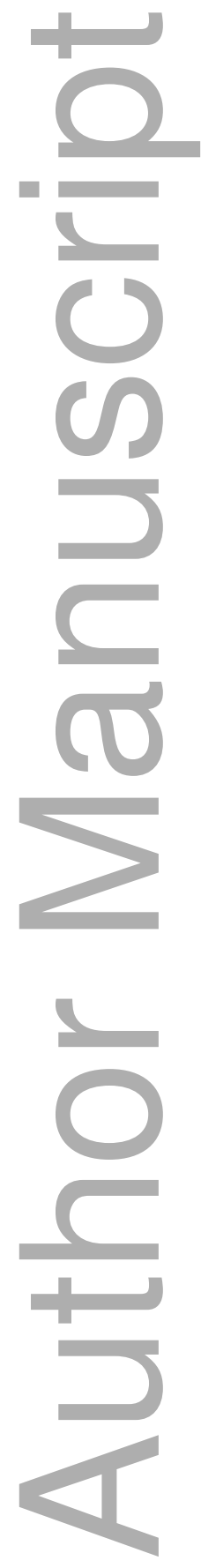


Table 2: Temporal relationships of microdeformation features and shatter cones (SC).

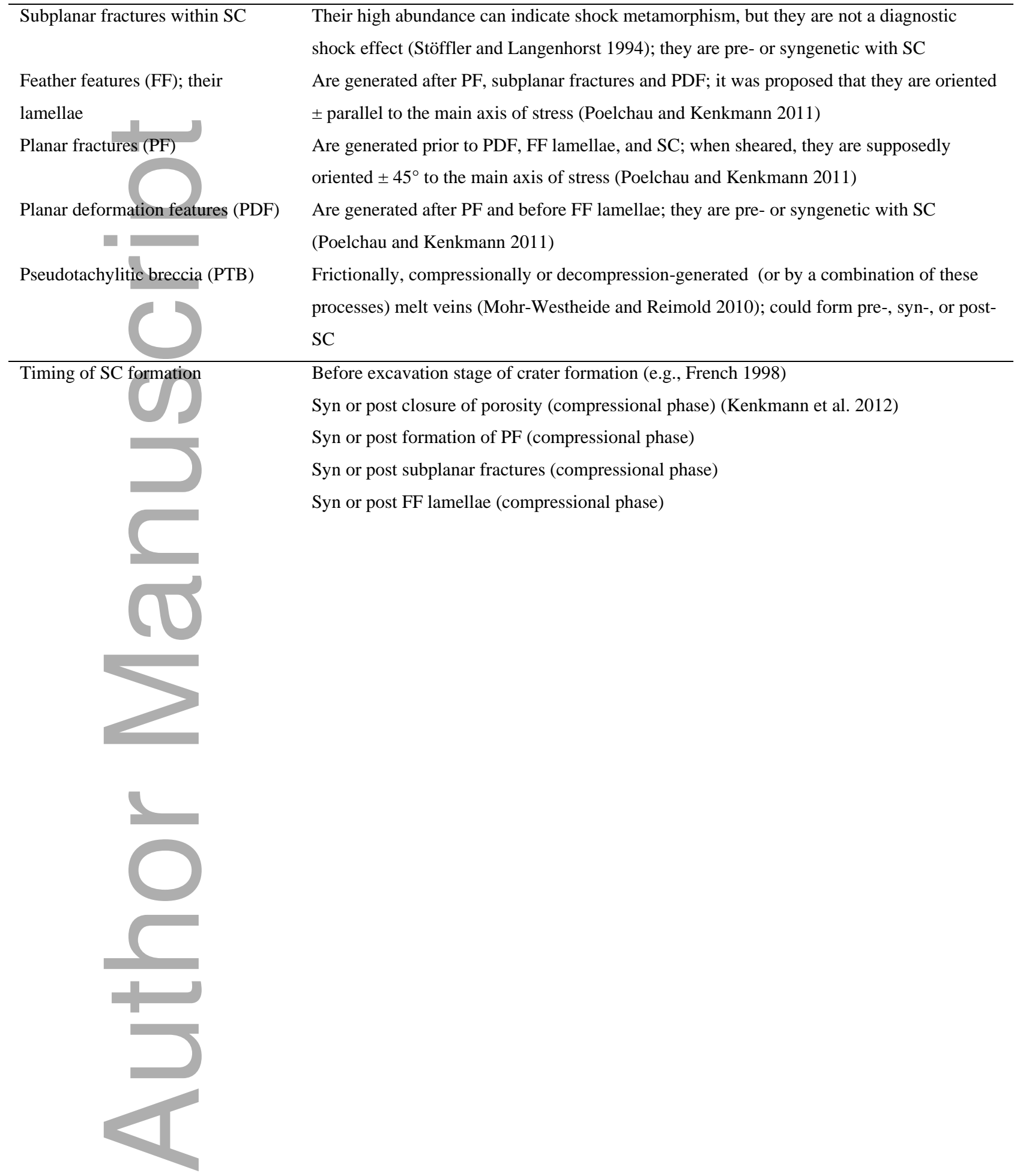




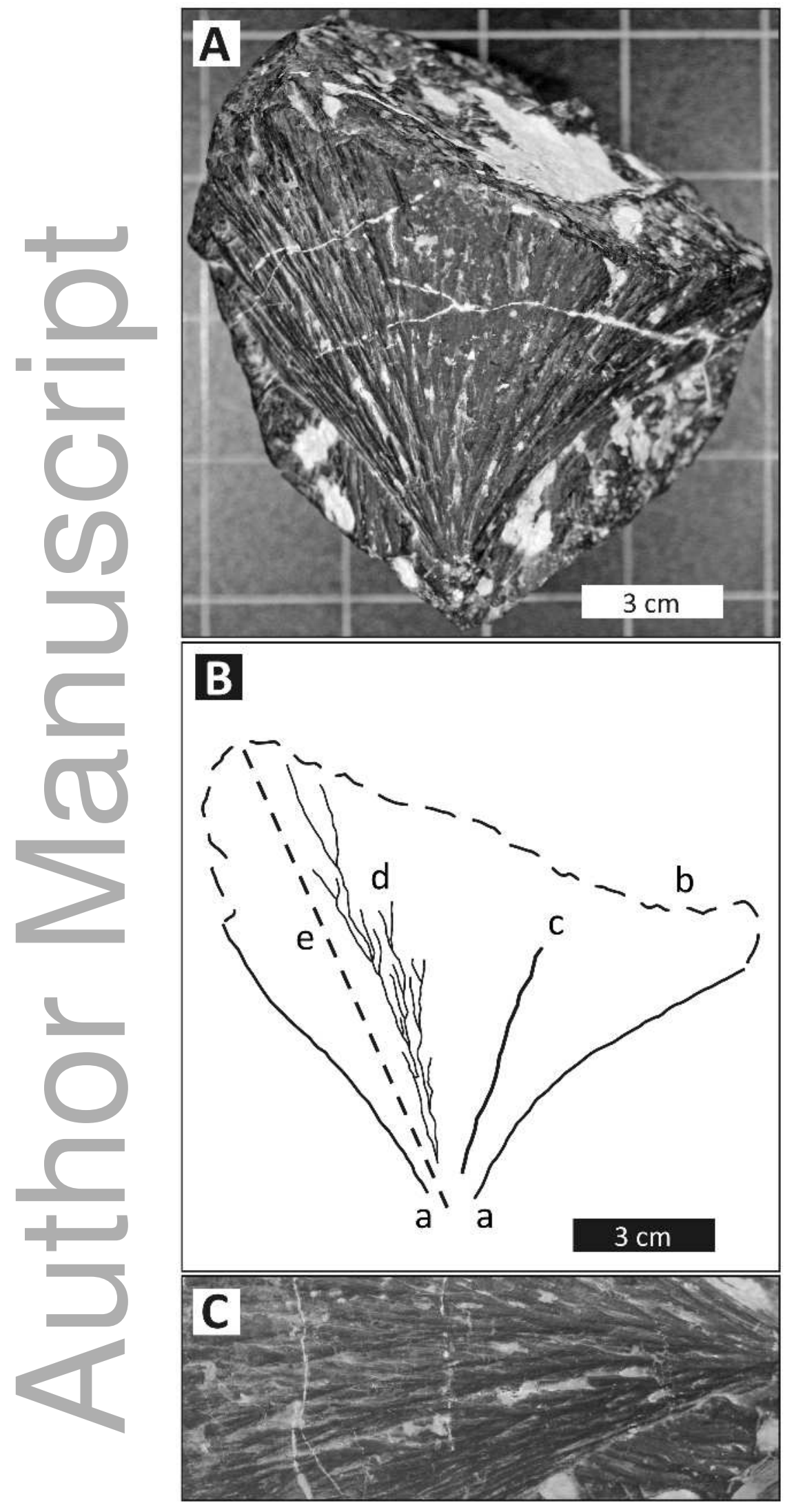

maps_12673-2457_f1.tif

This article is protected by copyright. All rights reserved 

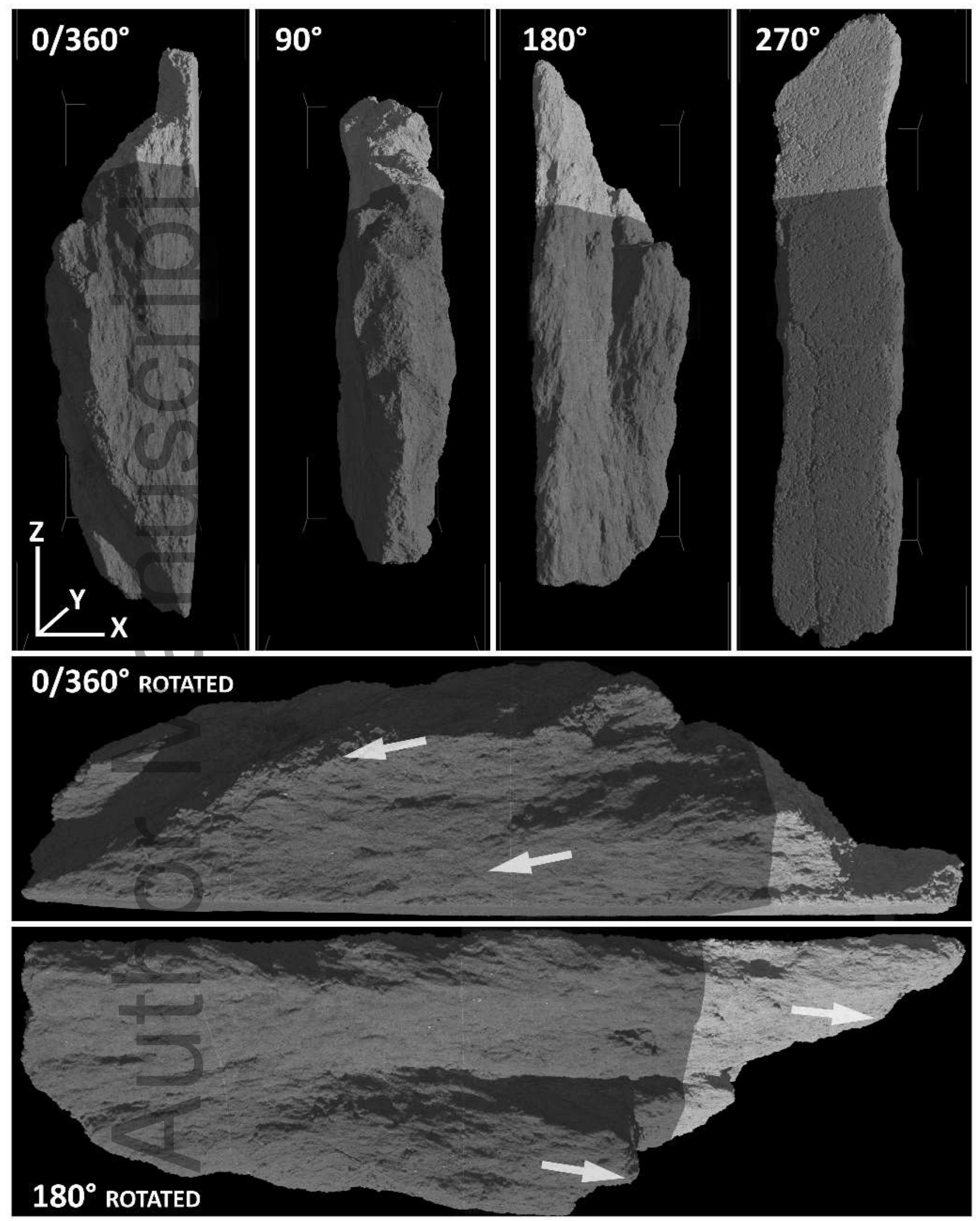

maps_12673-2457_f2.tif

This article is protected by copyright. All rights reserved 

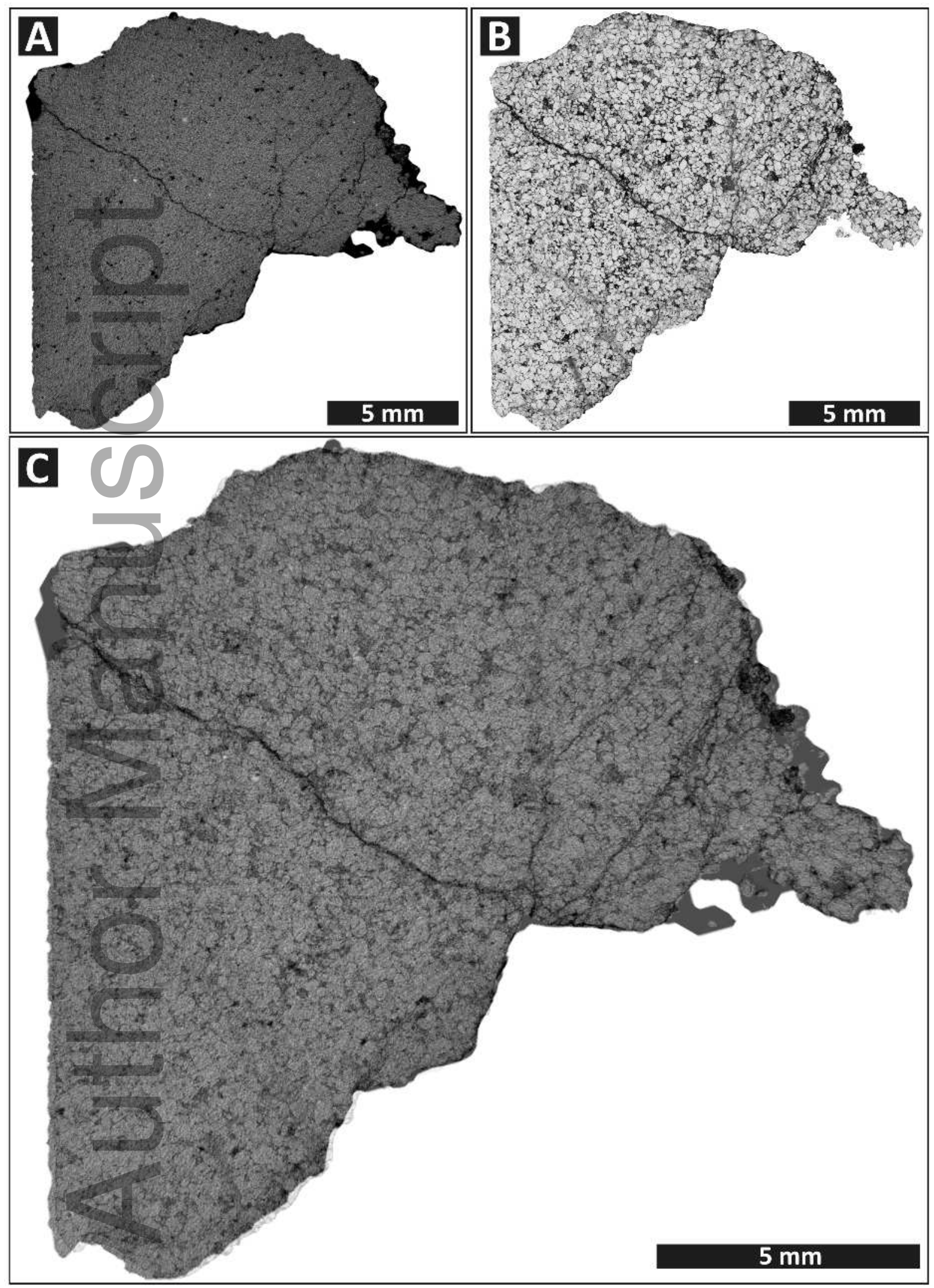

maps_12673-2457_f3.tif

This article is protected by copyright. All rights reserved 


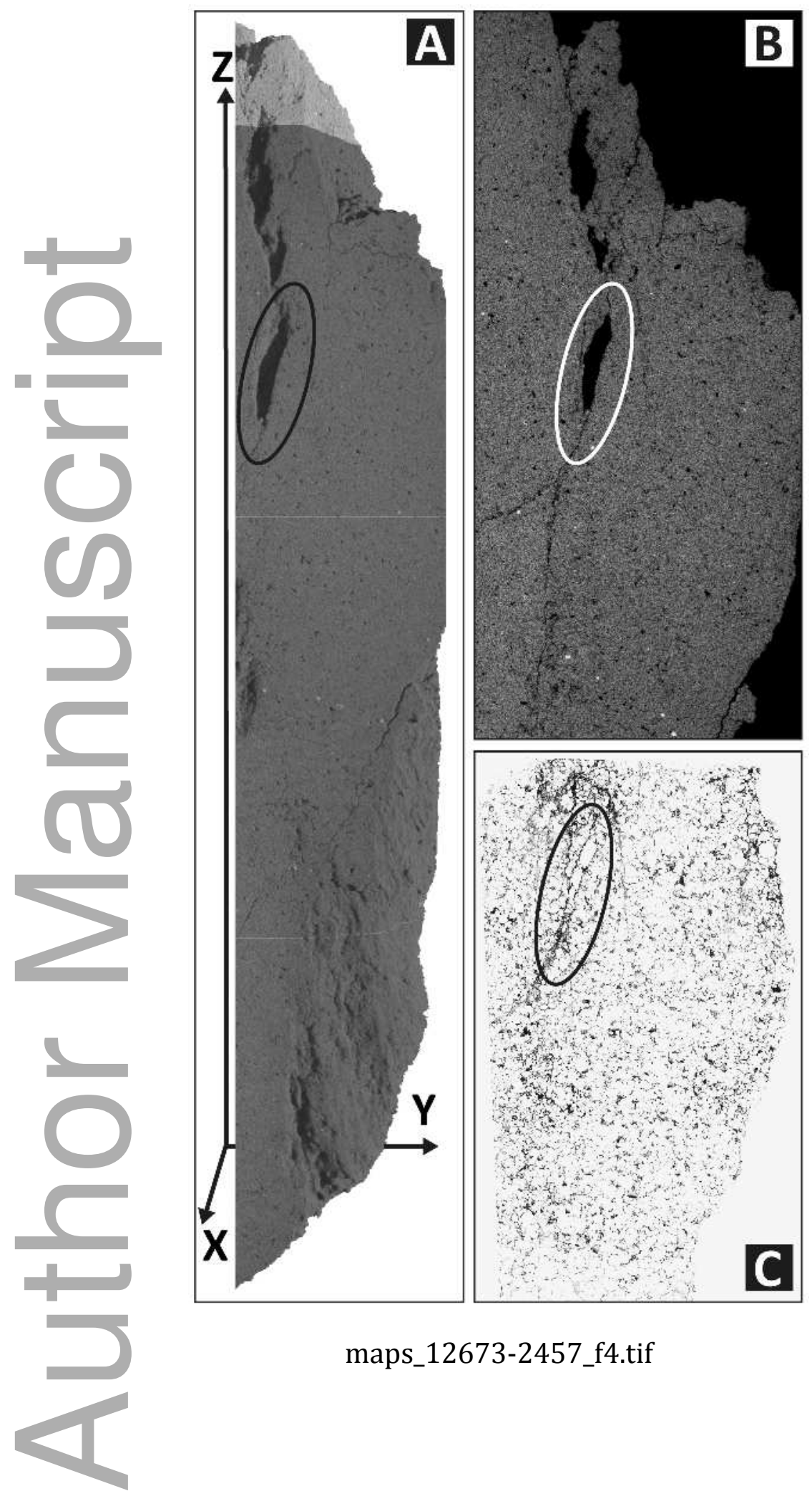

This article is protected by copyright. All rights reserved 


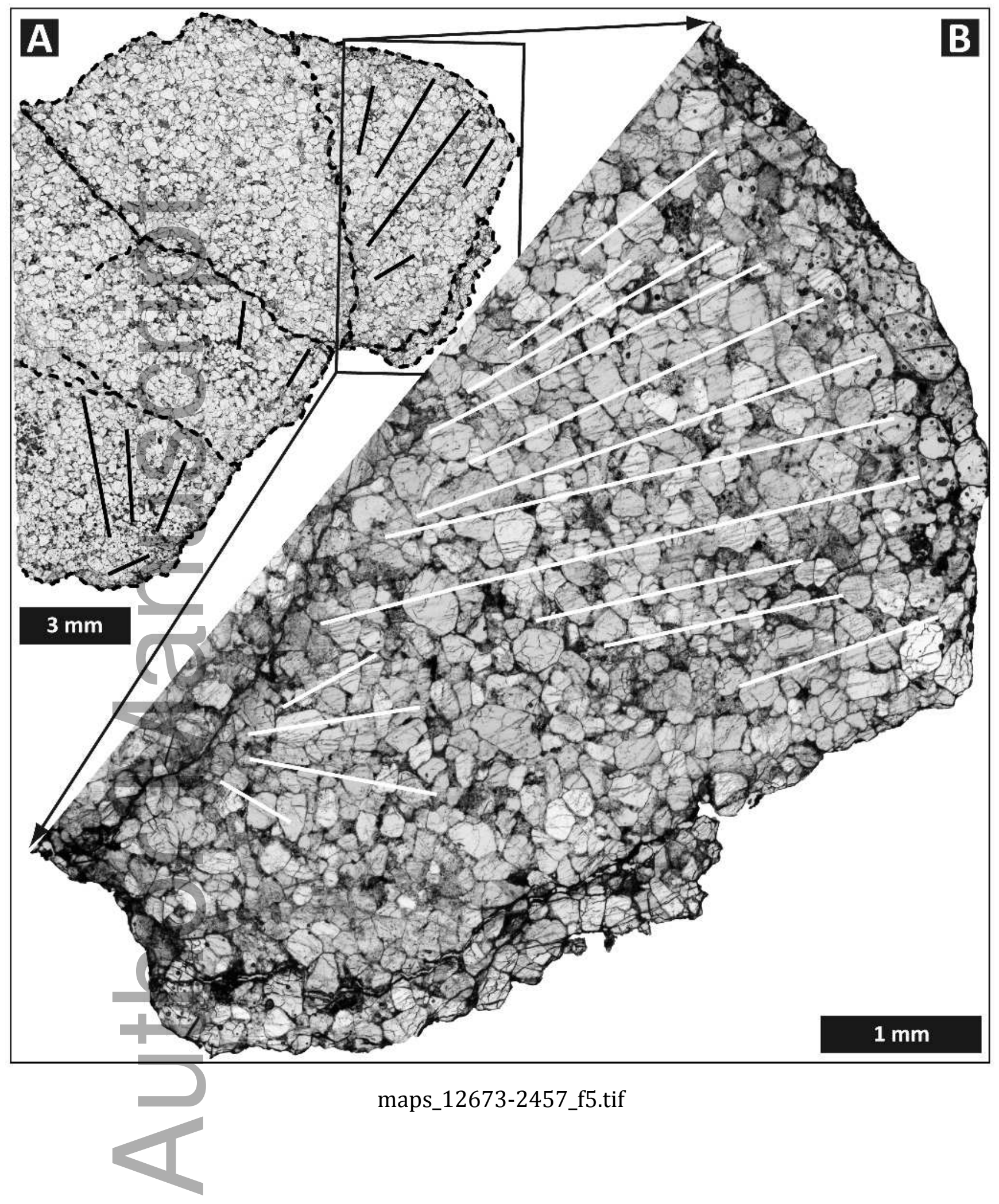

This article is protected by copyright. All rights reserved 

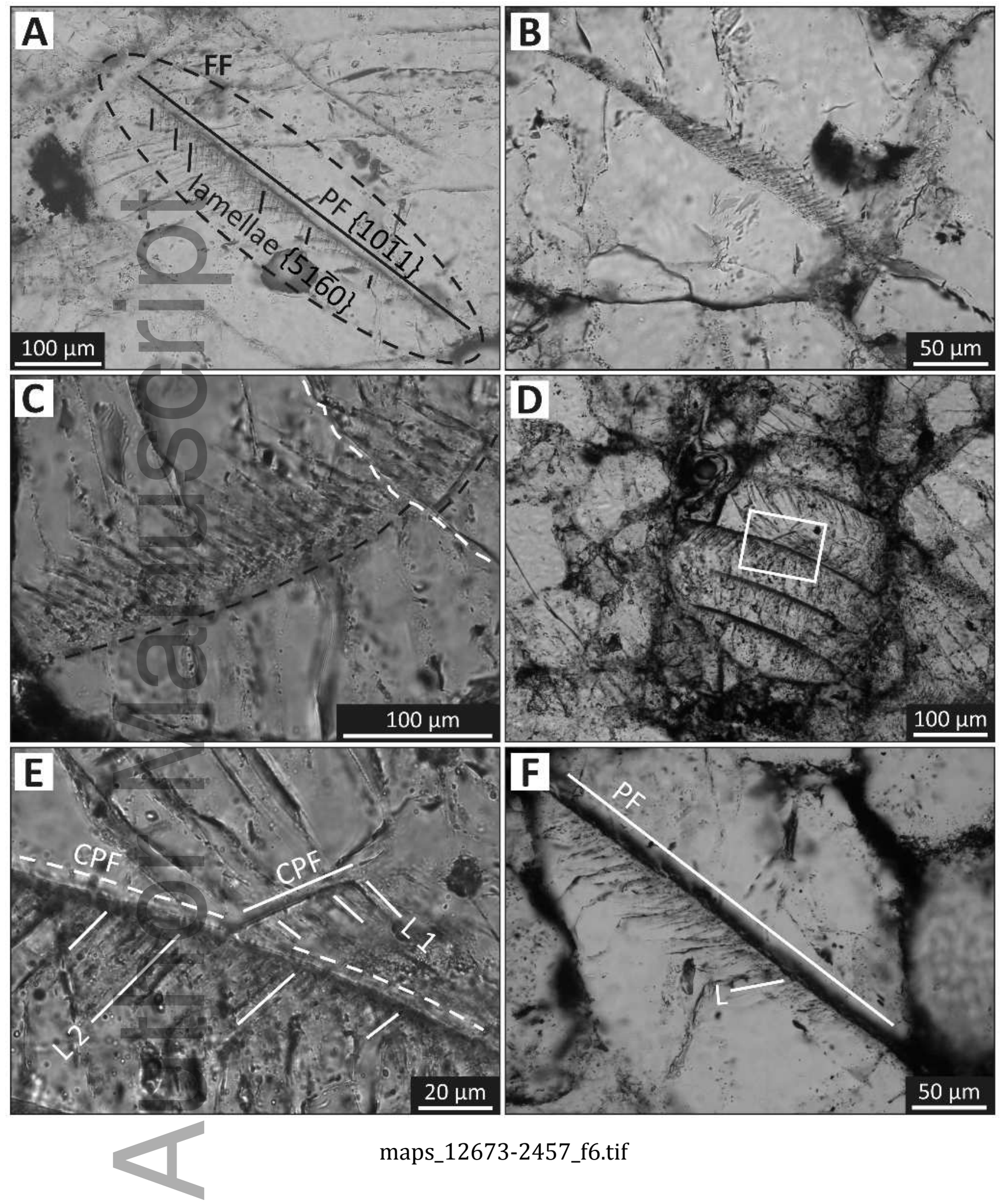

maps_12673-2457_f6.tif 

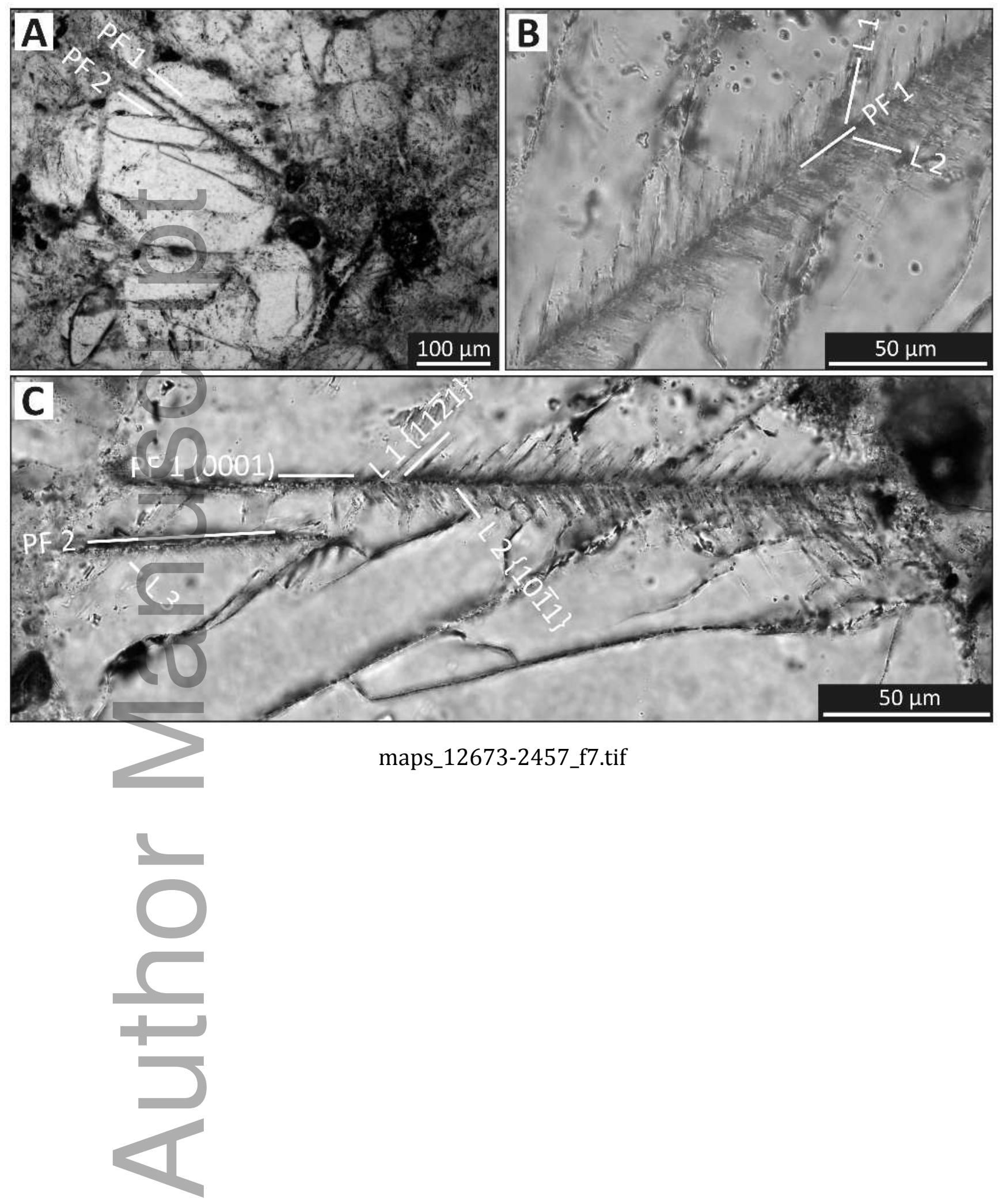

This article is protected by copyright. All rights reserved 


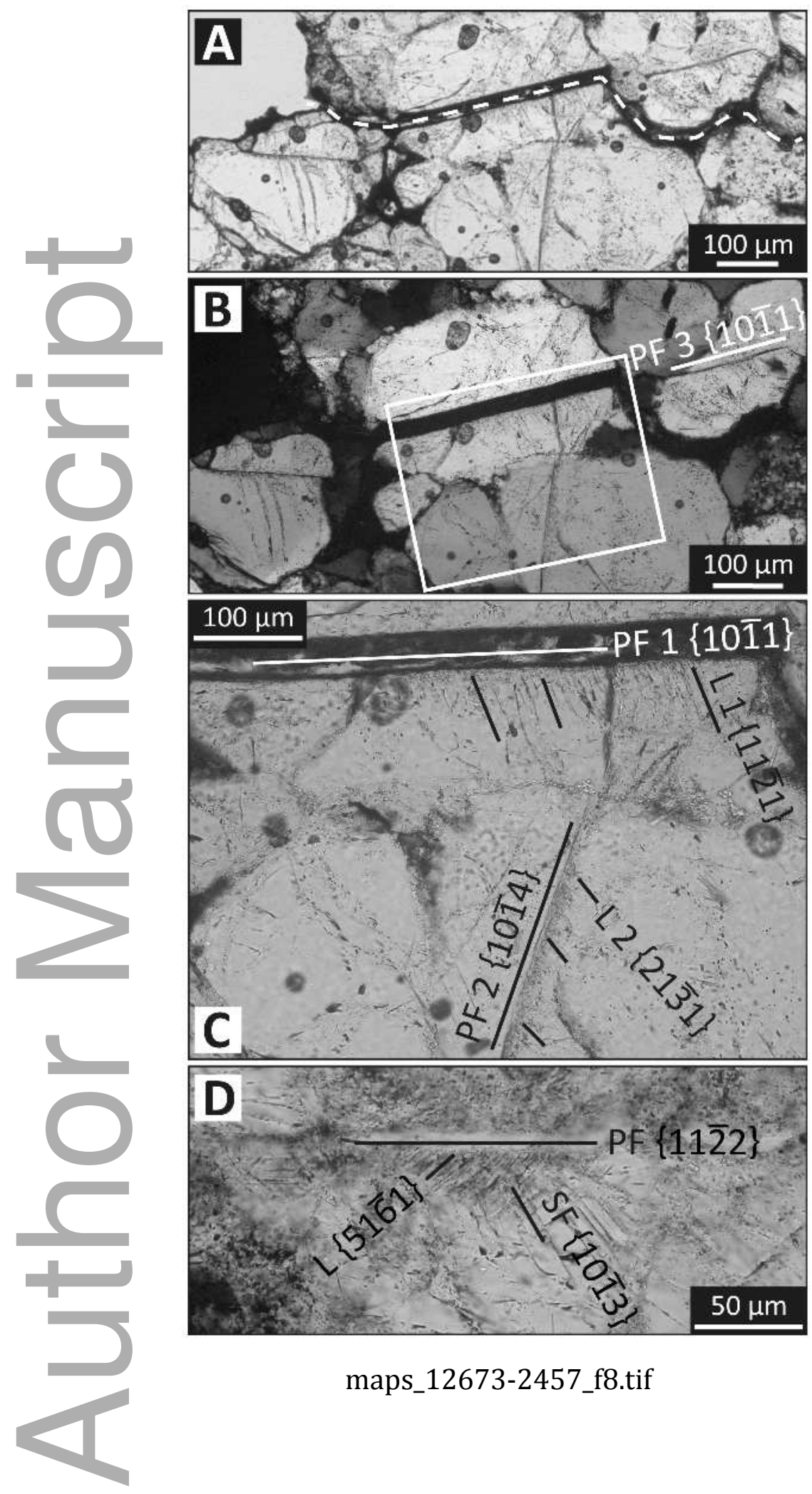

This article is protected by copyright. All rights reserved 


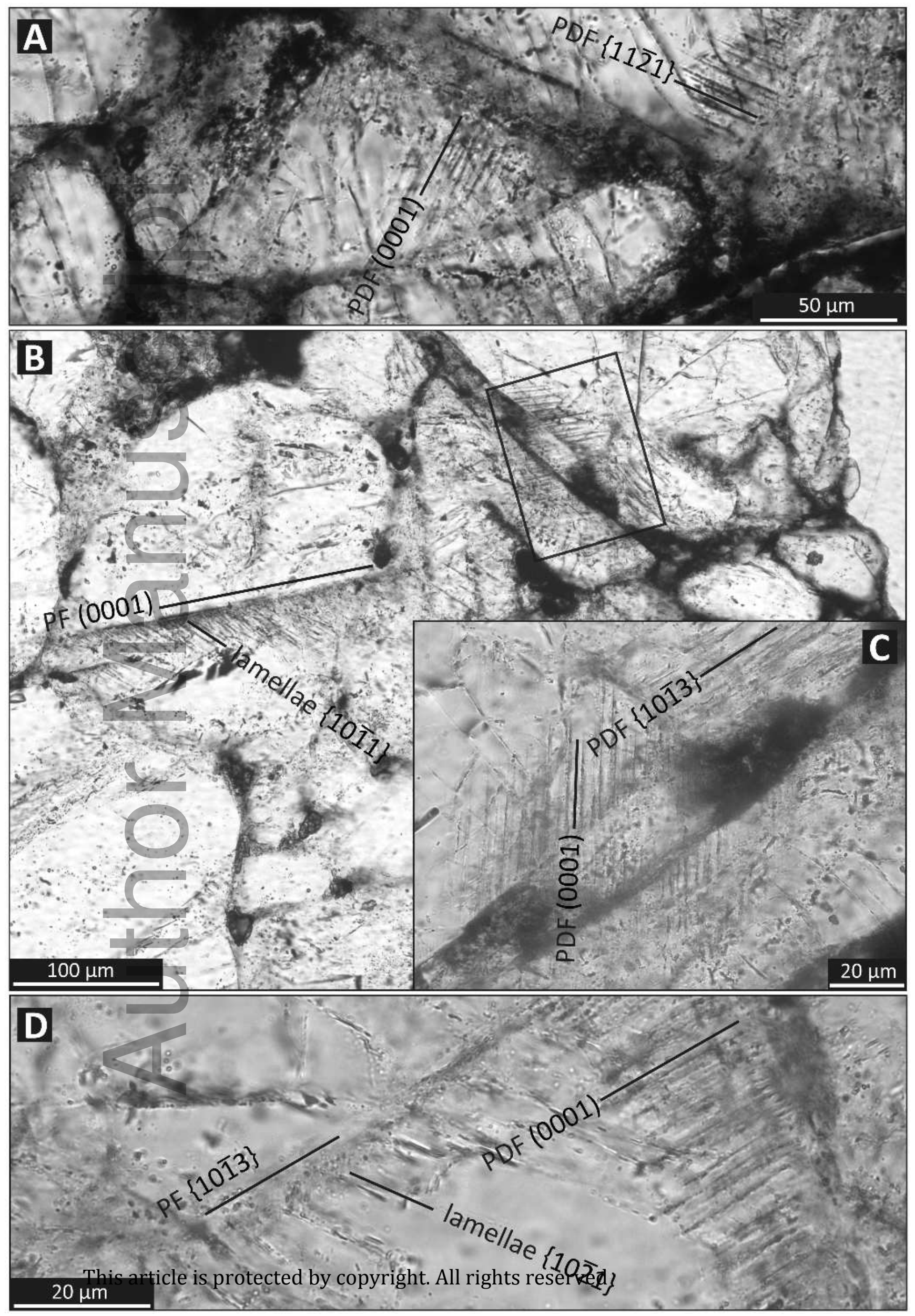




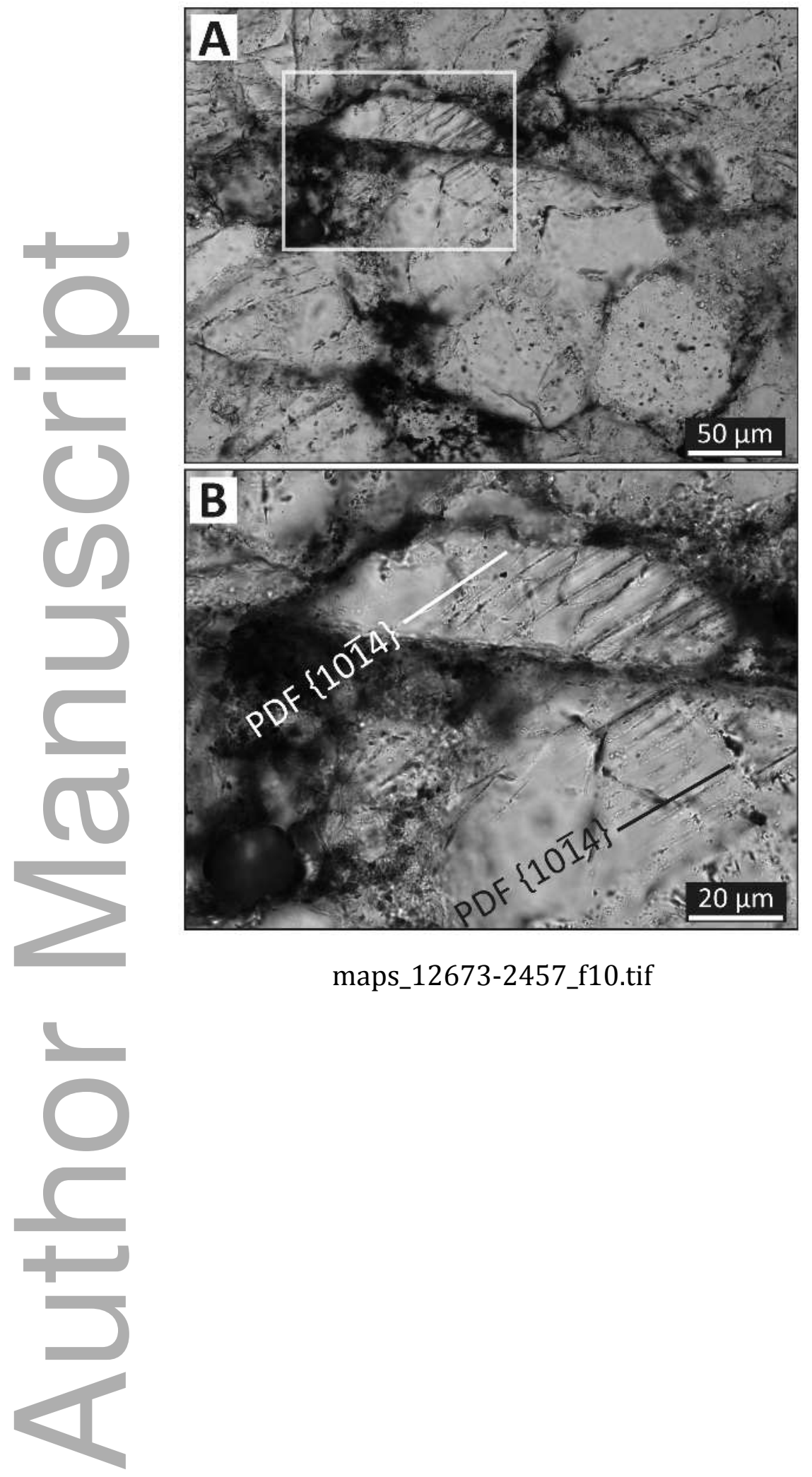

This article is protected by copyright. All rights reserved 


\section{University Library}

\section{- M M I N E R VA A gateway to Melbourne's research publications}

Minerva Access is the Institutional Repository of The University of Melbourne

Author/s:

Zaag, PT;Reimold, WU;Hipsley, CA

Title:

Microcomputed tomography and shock microdeformation studies on shatter cones

Date:

2016-08-01

Citation:

Zaag, P. T., Reimold, W. U. \& Hipsley, C. A. (2016). Microcomputed tomography and shock microdeformation studies on shatter cones. METEORITICS \& PLANETARY SCIENCE, 51 (8), pp.1435-1459. https://doi.org/10.1111/maps. 12673.

Persistent Link:

http://hdl.handle.net/11343/291579 